\title{
A Review of Gas Flow and Its Mathematical Models in Shale Gas Reservoirs
}

\author{
Bo-ning Zhang, ${ }^{1,2}$ Xiao-gang Li, ${ }^{1}$ Yu-long Zhao ${ }^{D},{ }^{1}$ Cheng Chang, ${ }^{3}$ and Jian Zheng ${ }^{4}$ \\ ${ }^{1}$ State Key Laboratory of Oil and Gas Reservoir Geology and Exploitation, Southwest Petroleum University, Chengdu, Sichuan, China \\ ${ }^{2}$ Chengdu North Petroleum Exploration and Development Technology Company Limited, Chengdu, Sichuan, China \\ ${ }^{3}$ PetroChina Southwest Oil \& Gasfield Company, Chengdu, Sichuan, China \\ ${ }^{4}$ Sichuan Changning Natural Gas Development Co. Ltd., Chengdu, Sichuan, China
}

Correspondence should be addressed to Yu-long Zhao; swpuzhao@swpu.edu.cn

Received 13 July 2020; Revised 4 October 2020; Accepted 4 November 2020; Published 1 December 2020

Academic Editor: Wei Wei

Copyright ( 2020 Bo-ning Zhang et al. This is an open access article distributed under the Creative Commons Attribution License, which permits unrestricted use, distribution, and reproduction in any medium, provided the original work is properly cited.

\begin{abstract}
The application of horizontal wells with multistage hydraulic fracturing technologies has made the development of shale gas reservoirs become a worldwide economical hotspot in recent years. The gas transport mechanisms in shale gas reservoirs are complicated, due to the multiple types of pores with complex pore structure and special process of gas accumulation and transport. Although there have been many attempts to come up with a suitable and practical mathematical model to characterize the shale gas flow process, no unified model has yet been accepted by academia. In this paper, a comprehensive literature review on the mathematical models developed in recent years for describing gas flow in shale gas reservoirs is summarized. Five models incorporating different transport mechanisms are reviewed, including gas viscous flow in natural fractures or macropores, gas ad-desorption on shale organic, gas slippage, diffusion (Knudsen diffusion, Fick diffusion, and surface diffusion), stress dependence, real gas effect, and adsorption layer effect in the nanoshale matrix system, which is quite different from conventional gas reservoir. This review is very helpful to understand the complex gas flow behaviors in shale gas reservoirs and guide the efficient development of shale gas. In addition to the model description, we depicted the type curves of fractured horizontal well with different seepage models. From the review, it can be found that there is some misunderstanding about the essence of Knudsen/Fick diffusion and slippage, which makes different scholars adopt different weighting methods to consider them. Besides, the contribution of each mechanism on the transport mechanisms is still controversial, which needs further in-depth study in the future.
\end{abstract}

\section{Introduction}

The reserves of unconventional gas reservoirs, such as shale gas, coalbed methane, tight gas reservoirs, and natural gas hydrate, are rich around the world. The annual production of them has become increasingly important to the global energy supply. As a kind of unconventional natural gas, shale gas is trapped in the source rock with self-accumulation, which is very tight with the permeability range from $\mathrm{nD}$ to $\mathrm{mD}$ [1-7]. The shale gas storage in shale reservoirs are mainly with the status of free gas, adsorbed gas, and dissolved gas. The adsorbed gas can account for up to $85 \%$ of the total. Shale gas has become an increasingly important source of natural gas since the success of exploitation in the United
States, and interest has spread to potential shale gas reservoirs around the world [1-3]. The horizontal wells and the multistage hydraulic fracturing technique have proven to be the key for the cost-effective development of such tight reservoirs [1, 8-11].

While shale gas reservoirs have the characteristic of multiscaled space from ultramicropores (pore diameter $<$ $0.7 \mathrm{~nm})$, micropores $(0.7 \mathrm{~nm} \sim 2 \mathrm{~nm})$, and mesopores $(2 \mathrm{~nm} \sim 50 \mathrm{~nm})$ to macropores $(>50 \mathrm{~nm})$, the small-scale nanopores of less than $10 \mathrm{~nm}$ dominate in shale $[1,2,5,6]$. Due to the complex pore size distribution and different gas storage mechanisms in shale gas reservoirs, which dominated by the viscous flow, slippage flow, Fick diffusion, Knudsen diffusion, surface diffusion, etc., gas transport mechanisms 
in shale gas reservoirs are very complicated and vastly different from those in conventional reservoirs. Although many models have been proposed and used to analyze the gas flow behaviors in nanoscale, some of which are extended to the application of numerical simulation and well testing, there is no unified model that can be acceptable in the industry so far. The related studies on such topics are being widely reported. The objective of this paper is to review the progress of gas transport mechanisms and some mathematical models developed for shale reservoirs [1], which is of great significance to establish a shale gas reservoir development strategy that is completely different from the conventional gas reservoir. Only by revealing the complex transmission mechanism of shale gas in the micro-nanopore system can an accurate mechanism model be provided for the numerical simulation and production dynamic evaluation of shale gas.

\section{Gas Flow and Transport Mechanisms}

2.1. Pore Types in Shale Gas Reservoirs. Shale gas reservoirs are typical unconventional oil and gas reservoirs, which consist of fine-grained and organic-rich sedimentary rock. Shale is both the reservoir and the source of oil and gas [1,9-12]. According to the International Union of Pure and Applied Chemistry (IUPAC), classification of pores in shale can be divided into organic intragranular pores, inorganic pores, and natural fractures [1].

In general, organic intragranular pores are formed only when thermal maturity (Ro) reaches $0.6 \%$ or above. When Ro is smaller than this value, few or no organic intragranular pores are developed. Organic pores in shale reservoirs are mainly developed during the thermal cracking of the hydrocarbon generation phase, and the sizes of organic pores range from $5 \mathrm{~nm}$ to $700 \mathrm{~nm}$ (as shown in Figure 1). Such organic nanometer pores are well developed in shale reservoirs, providing tremendous surface areas for shale gas adsorption as well as flow paths for gas flow $[1,6,7]$.

The inorganic pores in shale matrix can be categorized as residual primary intergranular pores (as shown in Figure 2(a)), intercrystalline pores (as shown in Figure 2(b)), and secondary dissolved pores formed by dissolution of unstable minerals (e.g., calcite and feldspar, as shown in Figure 2(c)).

There are lots of natural fractures that are developed in shale gas reservoirs (as shown in Figure 3). Most natural fractures in shale reservoir developed during the organic evolution of hydrocarbon source rocks, and they are intermittently open or closed with the changes of reservoir pressure. Therefore, for those shale gas reservoirs with mass microfractures, the permeability of the fracture system is sensitive to stress caused by closing of the microfractures during reservoir development. Similar to conventional dual-porosity reservoirs, natural fractures are considered to the main flow channel for shale gas [1].

2.2. Gas Adsorption and Desorption. The physical properties, pore types, and accumulation mechanisms of shale gas reservoirs are different from those of conventional gas reservoirs, resulting in natural gas to exist in diverse states in shale.

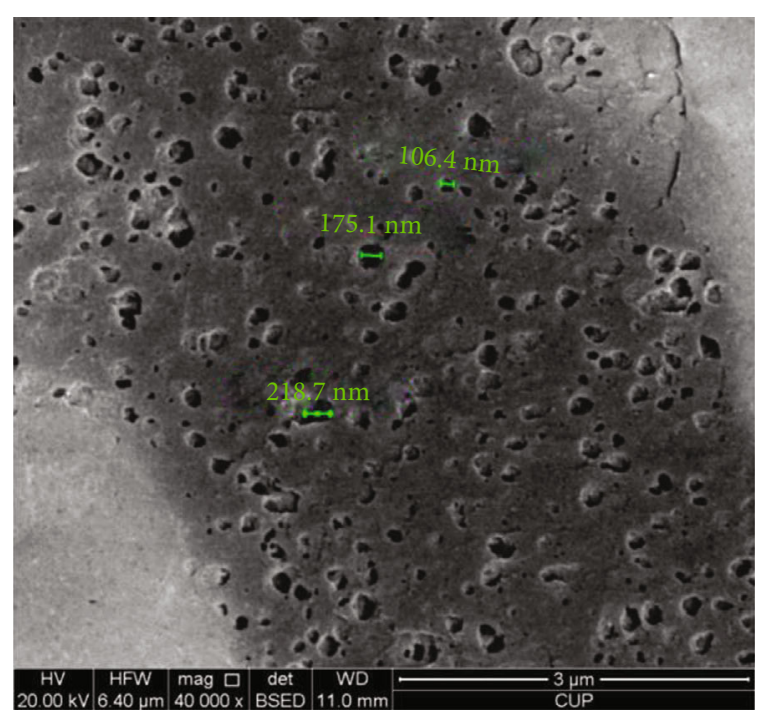

FIgURE 1: SEM images of shale organic pores [1].

Although a small amount of gas is dissolved in kerogen, asphaltene, liquid hydrocarbons, and formation water, the majority of natural gas exists in a free or an adsorbed state. Adsorbed shale gas is mainly adsorbed on the surface of organic matter with a single multimolecular layer, accounting for $20 \%$ to $85 \%$ of total reserves (as shown in Figure 4). Free gas is mainly stored in the pores of microfractures, inorganic and organic pores [14-16]. When the quantity of gas present in the reservoir is greater than the saturated adsorption capacity, free gas can exist $[17,18]$. The relative proportion of adsorbed and free gas varies with temperature, pressure, organic matter content and quality, degree of microfracture development, and formation water content (the gas storage status of shale gas reservoirs is shown in Figure 4) $[1,13,19]$.

As mentioned above, the amount of adsorbed gas can account for up to $85 \%$ of the gas reserve, which will be desorbed from the organic particle surface into free gas when the pressure is lower than the desorption pressure [1]. Therefore, the adsorption model is very important to describe the amount of gas in a given formation under certain conditions. According to the previous studies, there are two types of gas adsorption and desorption models-monomolecular layer model including the single layer adsorption model, such as Langmuir isothermal adsorption (L model); multimolecular layer model including the Freundlich adsorption model ( $\mathrm{F}$ model), BET model, bi-parameter BET model (B-BET model), Toth adsorption model ( $\mathrm{T}$ model), LangmuirFreundlich adsorption model (L-F model), extended Langmuir model (E-L model), three-parameter BET model (TBET model), and Dubinin-Radushkevich volume filling model (D-R model). These models can be used to calculate gas adsorption rate, pore size distribution, and desorption pressure. The formulas for these models are shown in Table $1[17,20,21]$.

Figure 5 shows the fitting curves of the methane isotherm adsorption data from Barnett formation by different adsorption models, and Figure 6 shows the fitting curves of the test data by samples from the target layer of Longmaxi shale in 


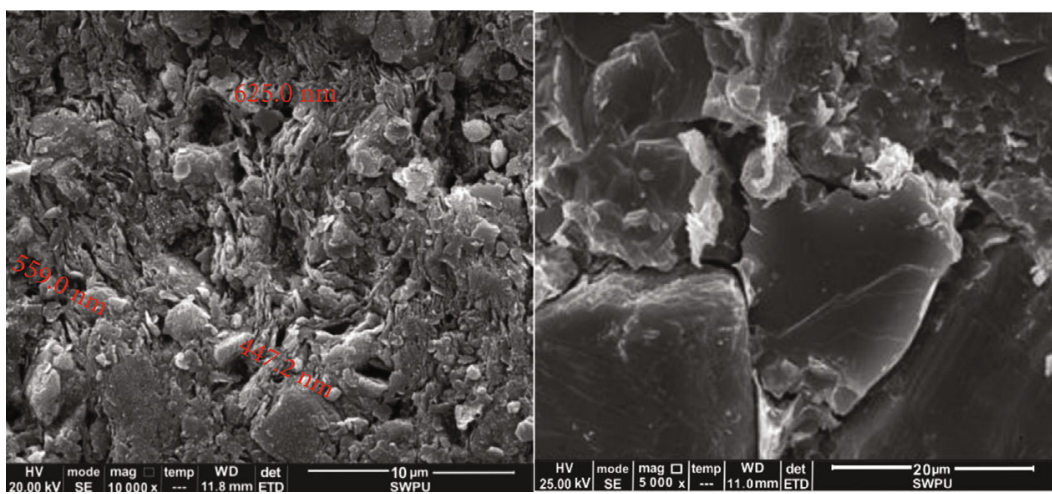

(a) Intergranular pores

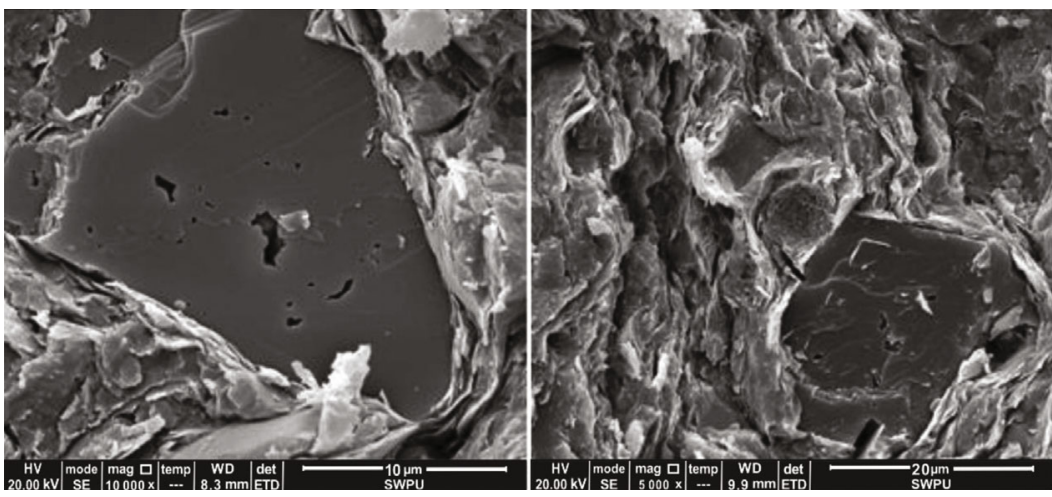

(b) Intragranular dissolved pores

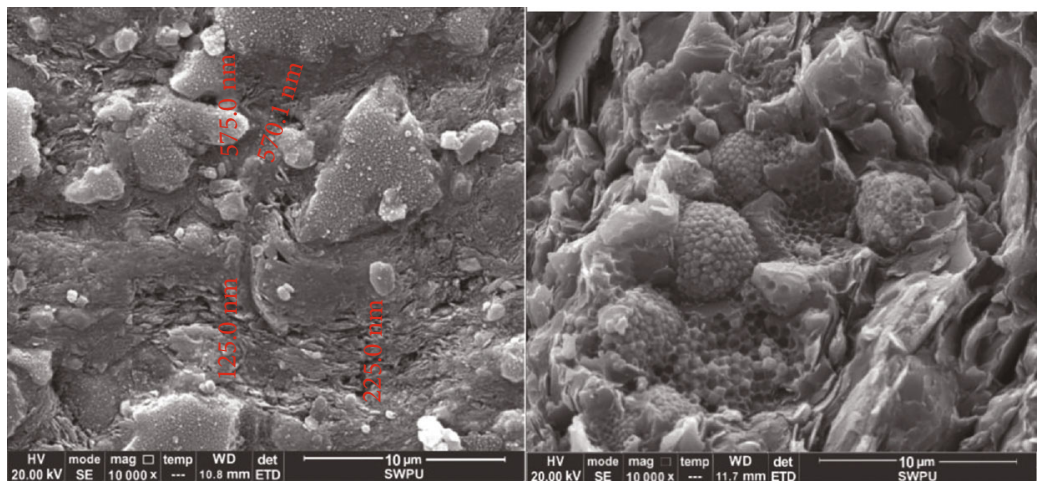

(c) Intercrystalline pores

FIgURE 2: SEM images of shale inorganic pores [1] (the sample from Changning area of Weiyuan, Sichuan, China).

southern Sichuan Basin. From the fitting results, the following results can be obtained: in general, the single molecular adsorption model is much better for the North American Barnett shale gas reservoirs, and the multimolecular layer adsorption model of T-BET is much better for the Changning shale gas reservoirs of China.

\section{Seepage Mechanism Models for Shale Gas Reservoirs}

Due to the complex pore space and gas accumulation dynamics in shale gas reservoirs, the movement of shale gas occurs via complex mechanisms, including adsorption-desorption, diffusion, and seepage [23]. The specific flow processes are as follows. With decreasing reservoir pressure, the gas adsorbed on the organic matter is desorbed. The desorbed gas then enters macropores, nanopores, and natural microfractures and becomes free gas. Due to the difference in gas concentration between kerogen/clay and organic nanopores, the gas flows to the low-pressure zone through diffusion (through matrix macropores or microfractures). Finally, free gas stored in matrix macropores and natural microfractures flows into wellbores and artificial hydraulic fractures under the pressure gradient $[23,24]$. Gas flow in macropores, fractures, and wellbores follows Darcy's law [25].

Generally, continuity hypothesis or molecular hypothesis can be used to model fluid flow in nanopores. The continuity hypothesis model can be used to describe the relationship between macroscopic fluid properties and spatial coordinates, which is widely used in fluid flow. Knudsen number 


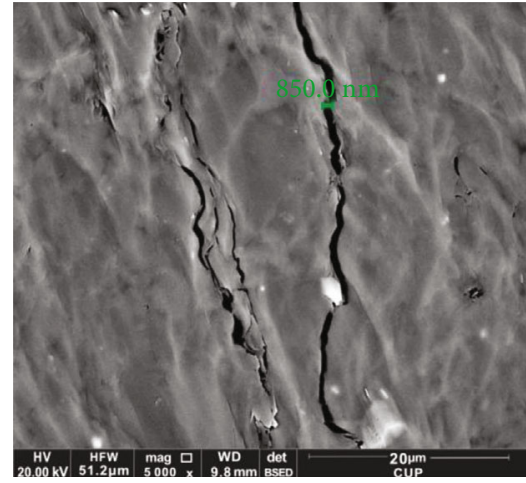

(a) Structural fractures

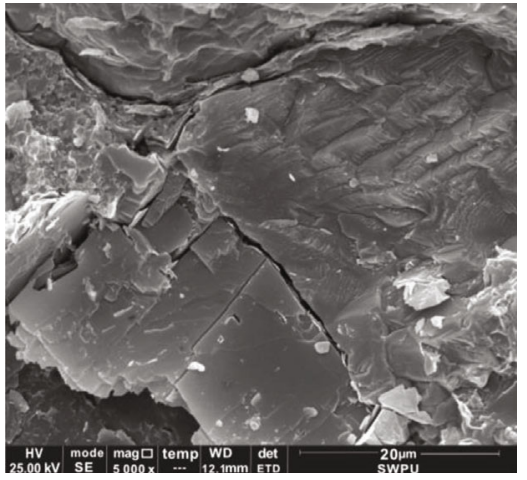

(b) Cleavage fractures

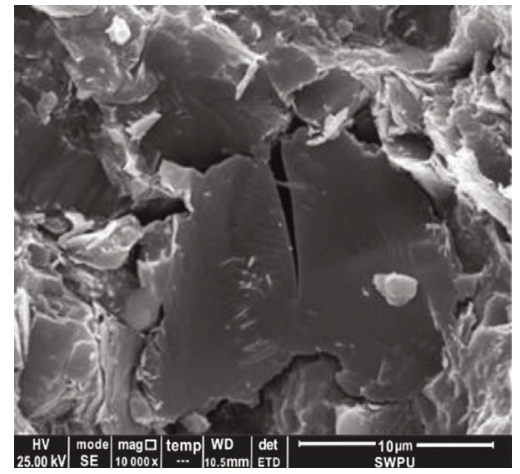

(c) Intragranular fractures

FIGURE 3: SEM images of natural fractures in shale [1].

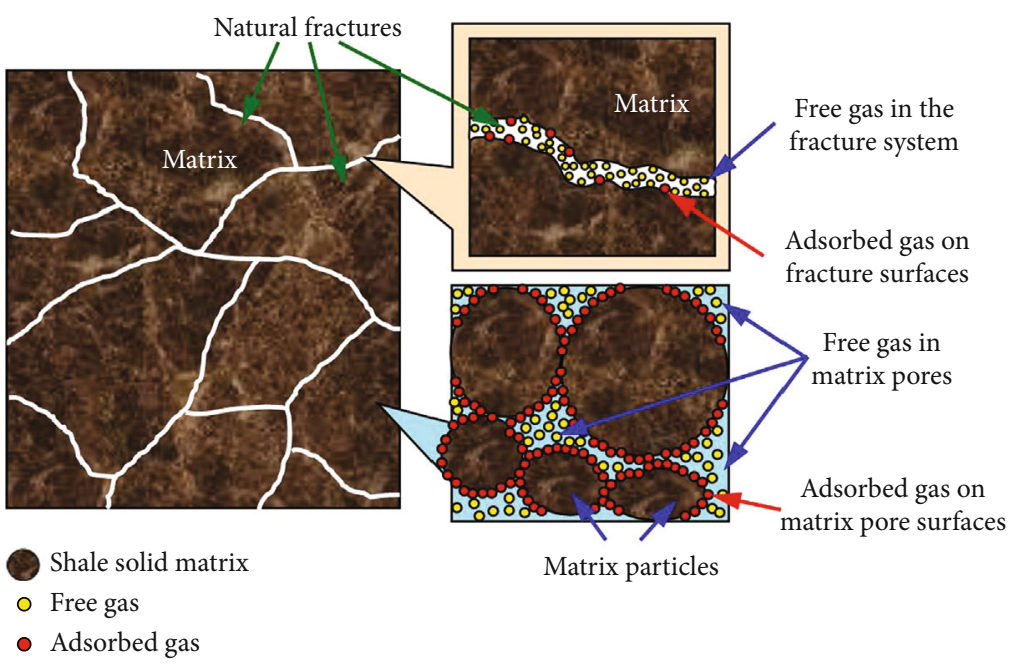

FIGURE 4: Schematic of gas storage in shale gas reservoirs [1, 13].

usually is used to justify if fluid flow satisfies the continuity hypothesis and then determine the fluid flow regime. Knudsen number $K_{\mathrm{n}}$ is defined as the ratio of gas molecular mean free path to the characteristic length of porous media, representing the relative degree of gas molecule collision with the gas molecules and pore walls. Its expression is

$$
K_{\mathrm{n}}=\frac{\lambda}{R_{\mathrm{h}}},
$$

where $\lambda$ is the gas molecular mean free path of gas $(\mathrm{nm})$ and $R_{\mathrm{h}}$ is the average hydraulic radius of pore media $(\mathrm{nm})$.

As shown in Figure 7 , when $K_{\mathrm{n}}<0.001$, the gas molecule velocity of a pore wall is zero, and Darcy's law is valid. This transport mechanism is also known as continuum flow. When $0.001<K_{\mathrm{n}}<10$, the gas molecule velocity of a pore wall is no longer zero, and, consequently, the gas flux is increased. Darcy's law is no longer valid, and this transport mechanism is referred to as rarefied gas transport. The rarefied gas transport is further subdivided into slip flow 
TABLE 1: Adsorption models and formulas [17, 20, 21].

\begin{tabular}{lc}
\hline Model & Formula \\
\hline Langmuir model (L model) & $V=V_{\mathrm{L}} \frac{p}{p_{\mathrm{L}}+p}$ \\
Freundlich empirical formula (F model) & $V=K_{\mathrm{b}} p^{n}$ \\
Bi-parameter BET model (B-BET model) & $\begin{array}{l}V_{\mathrm{m}} C p \\
\text { Toth adsorption model (T model) }\end{array}$ \\
Langmuir-Freundlich adsorption model (L-F model) & $V=\frac{V_{\mathrm{L}} K_{\mathrm{b}} p}{\left[1+\left(K_{\mathrm{b}} p\right)^{n}\right]^{1 / n}}$ \\
Extended Langmuir model (E-L model) & $V=\frac{V_{\mathrm{L}} K_{\mathrm{b}} p^{n}}{1+K_{\mathrm{b}} p^{n}}$ \\
Three-parameter BET model (T-BET model) & $V=\frac{V_{\mathrm{L}} K_{\mathrm{b}} p}{1+K_{\mathrm{b}} p+n \sqrt{K_{\mathrm{b}} p}}$ \\
Dubinin-Radushkevich volume filling model (D-R model) & $V_{\mathrm{m}} C p\left[1-(n+1)\left(p / p^{0}\right)^{n}+n\left(p / p^{0}\right)^{n+1}\right]$ \\
\hline
\end{tabular}

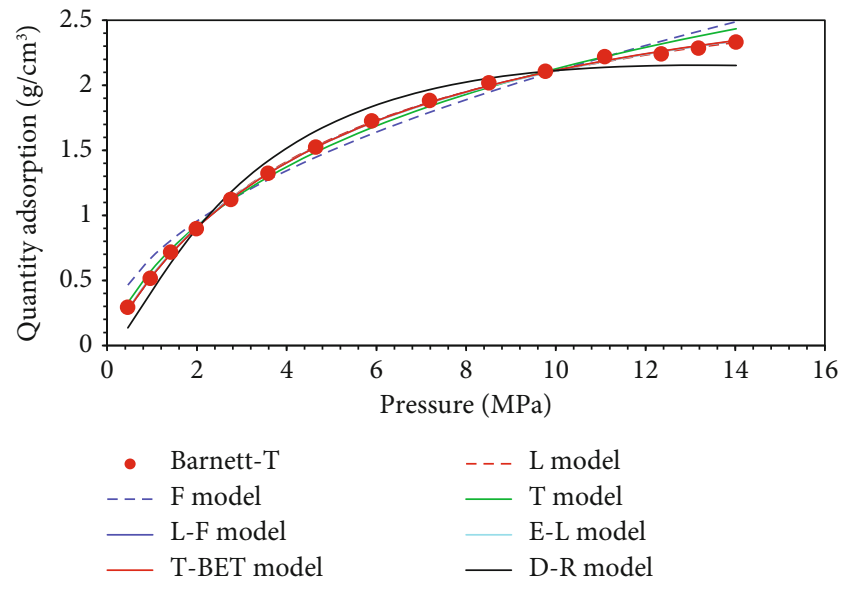

FIGURE 5: Fitting curves of different adsorption models for the Barnett shale reservoir sample [22].

$\left(0.001<K_{\mathrm{n}}<0.1\right)$, transition flow $\left(0.1<K_{\mathrm{n}}<10\right)$, and freemolecular flow $\left(10<K_{\mathrm{n}}\right)$. Under normal reservoir conditions of shale gas reservoirs, Knudsen number ranges from 0.0002 to $6[1,26]$.

By using Equation (1), the Knudsen number of pure methane under different pressure and different radius of pores with a temperature of $350 \mathrm{~K}$ can be calculated. And the results can be plotted as shown in Figure 8. We can clearly see that the gas flow in larger-scale pores, such as natural fractures, can be treated as a continuous flow. However, for small-scaled pores, the gas flow covers from slippage flow to transitional flow regimes, which is much more complicated than the continuous flow. The small scale pores always exist in the shale matrix.

To describe the mechanism of nanopore gas transport in continuous flow, slip flow, transition flow, and diffusion flow, scholars have proposed many coupling models considering dif-

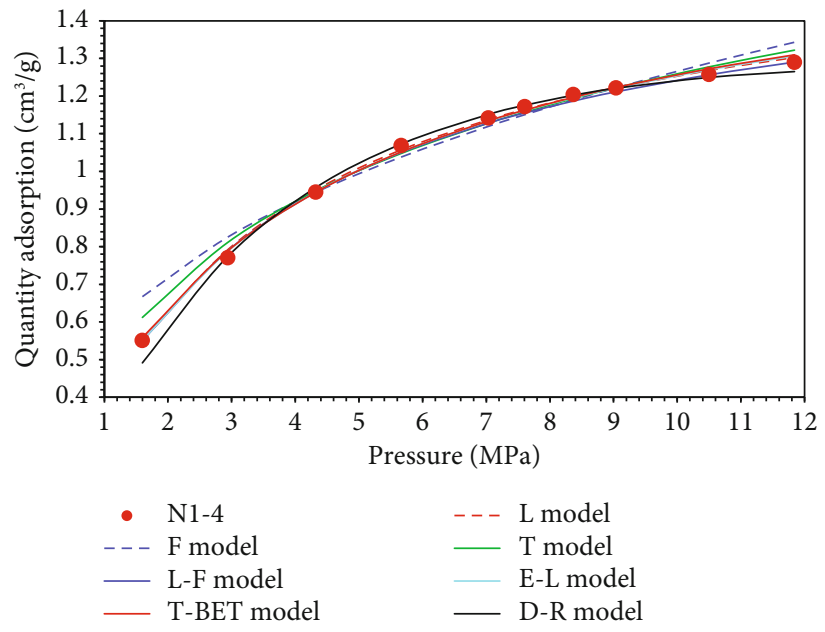

FIgURE 6: Fitting curves of different adsorption models for Changning shale reservoir.

ferent mechanisms. Ertekin et al. first established the coupling mechanism model considering continuous flow and Fick diffusion, and these two mechanisms directly adopted linear superposition. In this paper, the transport mechanism of gas in porous media was divided into bulk flow (intermolecular interaction), Knudsen diffusion (gas-solid interface interaction), and surface diffusion of the adsorption layer, among which the gas slip flow was essentially equivalent to Knudsen diffusion [28].

In 2007, Javadpour et al. proposed an apparent permeability model of shale matrix considering the dual mechanism of Knudsen diffusion and slip flow. The model had a similar form to the Darcy equation and was easy to apply [29]. Then, based on the Javadpour model, Darabi et al. introduced the influence of the pore-throat structure characteristics of the shale matrix on the gas flow law (the tortuosity and roughness, etc.) by introducing the fractal theory [30]. 


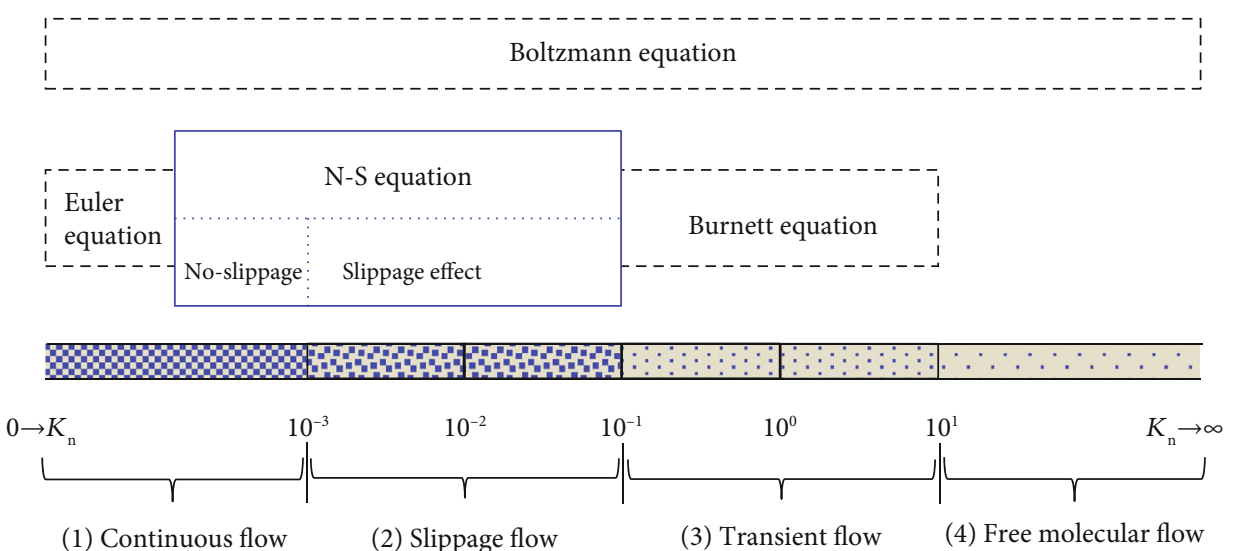

FIGURE 7: Knudsen number regimes [27].

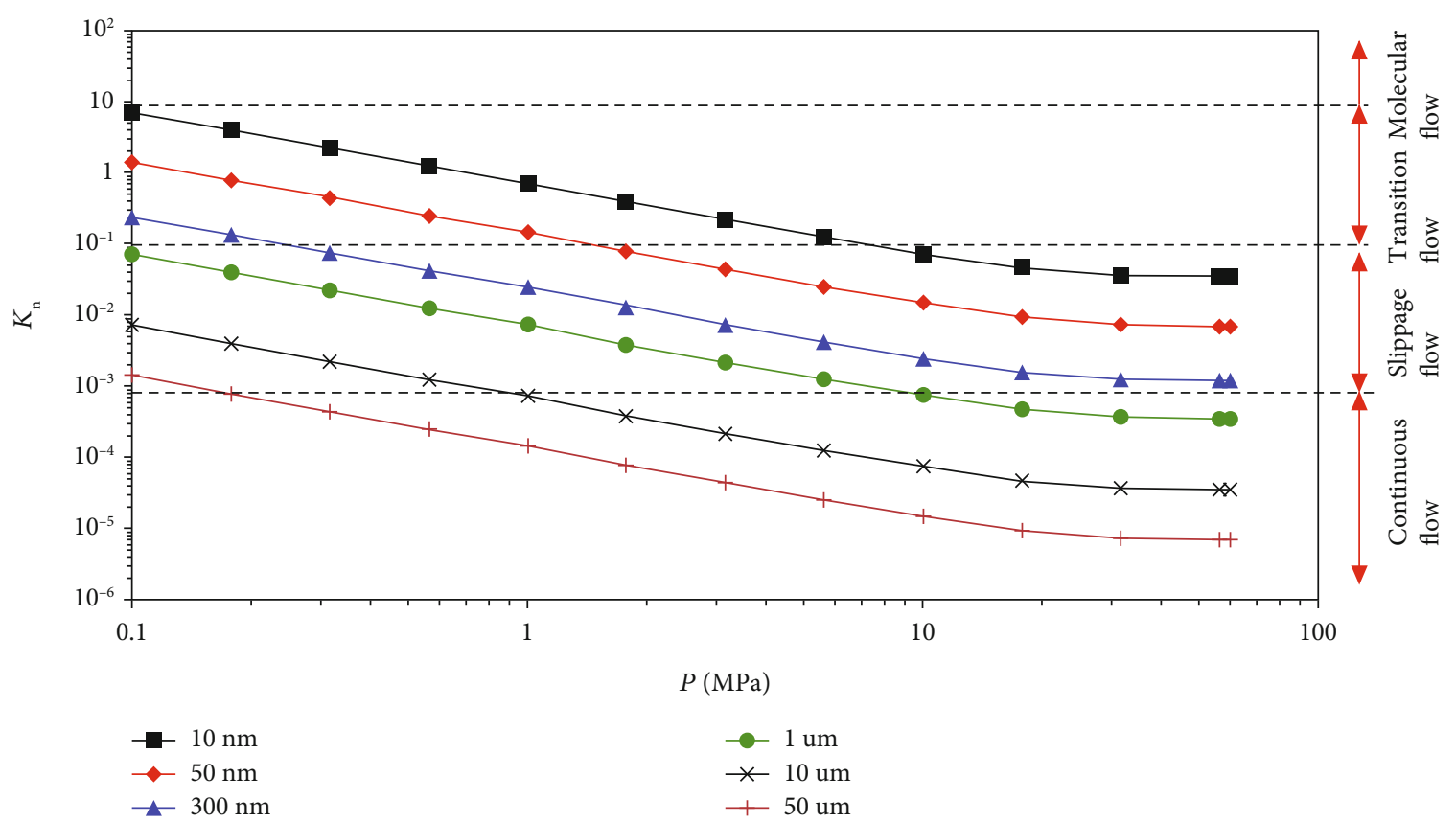

FIgURE 8: Flow regimes of methane under different pressure and pore radius.

In 2012, Shabro et al. established a shale gas flow mechanism model that considers dissolved gas diffusion, slip flow, Knudsen diffusion, and Langmuir desorption in kerogen [31]. In 2014, Mi et al. studied the apparent permeability model of the fracture system and matrix system, respectively, by linear superposition. The methods of establishing these models were based on Javadpour's model, which was to superimpose the slip flow and the diffusion. The difference was that Mi et al. divided the flow types into Knudsen diffusion, transitional diffusion, and Fick diffusion according to the $K_{\mathrm{n}}$ number [32].

In 2015, based on the transport mechanisms of slip flow and Knudsen diffusion, $\mathrm{Wu}$ et al. established a nanopore shale gas transmission model according to the ratio of the collision frequency between molecules and the collision frequency of molecules to the wall of the pores as the weighting factors of the slip flow and the Knudsen diffusion [26]. In the same year, Sheng et al. proposed a comprehensive model for coupling gas viscous flow, slip flow, Knudsen diffusion, and surface diffusion based on the weighted superposition of Wu et al.'s [33]. Subsequently, according to different transport mechanisms and pore structure characteristics of the gas, various multiple apparent permeability models were successively proposed by using different superposition methods $[34,35]$.

In 2017, Li et al. published their research results in the Journal of Physics that both Nusen diffusion and surface diffusion are related to the gas-solid interaction at the interface [36]. Knudsen diffusion is a diffusion phenomenon that occurs after gas molecules collide with the wall surface. Surface diffusion is a process in which gas molecules continuously jump between adsorption sites on the pore surface. In both cases, the velocity of the gas molecules on the wall surface is not zero, which is consistent with the slip 
phenomenon. Li et al. believed that it is debatable to superimpose the Knudsen diffusion and slip flow, or to superimpose the slip flow and surface diffusion, or to superimpose these three transport mechanisms in flow models. Since the shale gas mass transport mechanism was introduced from the theory of rarefied gas dynamics, the aerodynamic researcher also thought that, from the point of view of rarefied gas, slip flow was essentially the same as Knudsen diffusion, which was determined by the Boltzmann equation and gas-solid interaction, but the coefficients were different under different $K_{n}$ $[37,38]$. After that, Cai et al. proposed a very interesting apparent permeability model by accounting for three major fluid flow mechanisms in shale stratum, which is modeled as a $3 \mathrm{D}$ fractal media. This model can present the gas flow in shale pore media more accurately $[39,40]$.

Table 2 lists the apparent permeability models proposed by different scholars in recent years for different transport mechanisms of shale gas under different coupling methods. In general, scholars believe that the fluid flow mechanism in the micro-nanopore system of shale gas mainly includes viscous flow, slip flow, Knudsen diffusion, surface diffusion, adsorption layer effect, reservoir pore structure characteristics, and stress sensitivity. However, there are still differences in the essential relations between various mechanisms, which need to be further studied. Meanwhile, the existing mechanism models are not combined with the actual characteristics of pore-throat scale distribution. Whether the same mechanism model is applicable to reservoirs of various types of scales is still debatable and remains to be further studied. In order to better guide the efficient development of shale gas, only by revealing the complex transmission mechanism of shale gas in the micro-nanopore system can we provide an accurate mechanism model for shale gas numerical simulation and production dynamic evaluation.

$R$ is the molar gas constant; $M$ is the molar mass; $k_{\text {app }}$ is the apparent permeability; $k_{0}$ is the absolute permeability; $\bar{\lambda}$ is the mean free path at mean pressure; $r$ is the pore radius; $a$ is the dimensionless rarefaction coefficient (when multiply by $K$ ), or tangential momentum accommodation coefficient (when in the denominator); $a_{0}$ is the rarefaction dimensionless coefficient at $K_{\mathrm{n}} \rightarrow 0 ; a_{1}$ and $a_{2}$ are the fitting dimensionless constants that are obtained through molecularsimulation and experimental data, respectively; $D_{\mathrm{f}}$ is the fractal dimension of the pore surface; $\delta^{\prime}$ is the ratio of normalized molecular size to local average pore diameter; $D_{\mathrm{k}}$ is the Knudsen diffusion coefficient; $c_{\mathrm{g}}$ is the gas compressibility; $c_{\phi}$ is the dimensionless material-specific constant; $\sigma_{\mathrm{m}}$ is the mean in situ effective stress; $\zeta_{\mathrm{mb}}$ is the dimensionless correction factor of apparent permeability in nanopores of SGRs; $T$ is the temperature; $\omega_{\mathrm{m}}$ is the poromechancial-response dimensionless coefficient of shale matrix; $\omega_{\mathrm{s}}$ is the sorptioninduced-swelling-response dimensionless coefficient of shale matrix; $\eta$ is the gas viscosity; $C_{\text {ads }}$ is the adsorbed-phase concentration; $\rho_{\text {ads }}$ is the adsorbed-phase density; $R_{\mathrm{e}}$ is the effective radius of the nanocapillary tube for free gas transport; $R_{0}$ is radius of the nanocapillary tube; $D_{\mathrm{S}}$ is the diffusion coefficient; $\alpha_{\rho}$ is the density ratio of adsorbed gas to free gas; $n$ is the number of adsorbed layer; $p_{0}$ is the saturated adsorption pressure of gas; $Z$ is the gas deviation factor; $D_{\mathrm{S} 0}$ is the corrected diffusivity; $\tau$ is the tortuosity; $\rho_{l}$ is the sorbent density; $\theta$ is the surface coverage; $\delta$ is the molecular diameter; $p_{\mathrm{L}}$ is the Langmuir pressure; $C_{\mathrm{L}}$ is the maximum gas capacity; $\psi$ is the TOC; $w_{\mathrm{v}}$ and $w_{\mathrm{k}}$ are the weight of the viscous molar flux and the Knudsen diffusion molar flux, respectively; $\psi_{\text {or }}$ is the ratio of pores with adsorption capacity to total pores; $\omega_{\text {or }}$ and $\omega_{\text {in }}$ are coefficients of variation in pores with and without adsorption.

Taking the model proposed by Zhang et al. as an example, considering the properties of porous media and adsorptive gas occupation, the apparent permeability of shale matrix can be expressed as the sum of bulk transport and adsorbed gas transport in the following form $[1,5,54]$ :

$$
k_{\text {app }}=k_{\text {slip }}+k_{\text {Knudsen }}+k_{\text {surface }} .
$$

For slippage flow, considering the effect of stressdependence and adsorbed layer, its equivalent permeability could be expressed as

$$
k_{\text {slip }}=\gamma_{\mathrm{b}} F\left(K_{\mathrm{n}}, p\right) \frac{r_{\mathrm{eff}}^{2}}{8}
$$

For Knudsen diffusion, its equivalent permeability has the following form [5]:

$$
k_{\text {Knudsen }}=\gamma_{\mathrm{b}}\left(\delta^{\prime}\right)^{D_{\mathrm{f}}-2} D_{\mathrm{K}} c_{\mathrm{g}} \mu
$$

Considering the influences of gas coverage ratio, porous media properties, and real gas effect, the equivalent permeability of surface diffusion could be expressed as

$$
\begin{gathered}
k_{\text {surface }}=\gamma_{\mathrm{s}} D_{\mathrm{s}} V_{\mathrm{L}} \theta_{\text {real }} \frac{\mu Z}{p^{2}} \frac{T p_{\mathrm{sc}}}{T_{\mathrm{sc}}}, \\
F\left(K_{\mathrm{n}}, p\right)=1+\frac{8 \omega p_{\mathrm{r}}}{p} K_{n}
\end{gathered}
$$

where $V_{\mathrm{L}}$ is the Langmuir volume, $\mathrm{m}^{3} / \mathrm{m}^{3} ; D_{\mathrm{k}}$ is the Knudsen diffusion coefficient, $\mathrm{m}^{2} / \mathrm{s} ; D_{\mathrm{s}}$ is the surface diffusion coefficient, $\mathrm{m}^{2} / \mathrm{s} ; c_{\mathrm{g}}$ is gas concentration, $\mathrm{mol} / \mathrm{m}^{3} ; \mu$ is gas viscosity, $\mathrm{Pa} \bullet s ; p_{\mathrm{r}}$ is the reference pressure, $\mathrm{Pa} ; K_{\mathrm{n}}$ is the Knudsen number, dimensionless; $D_{\mathrm{f}}$ is the fractal dimension of pore surface, dimensionless; $p$ is reservoir pressure, $\mathrm{Pa} Z Z$ is the gas deviation factor, dimensionless; $T_{\mathrm{sc}}$ and $P_{\mathrm{sc}}$ are the temperature and pressure at standard condition; $b$ is the Langmuir equilibrium adsorption constant, $\mathrm{Pa}^{-1} ; \omega$ is a parameter related to gas-solid interaction; $\gamma_{\mathrm{b}}$ is the correction factor from single capillary model to upscaled porous media model for bulk phase; $\gamma_{s}$ is the correction factor from single capillary model to upscaled porous media model for surface diffusion.

$\theta_{\text {real }}$ is the gas coverage ratio on solid surfaces considering the real gas effect and thermodynamic phase changes, which 


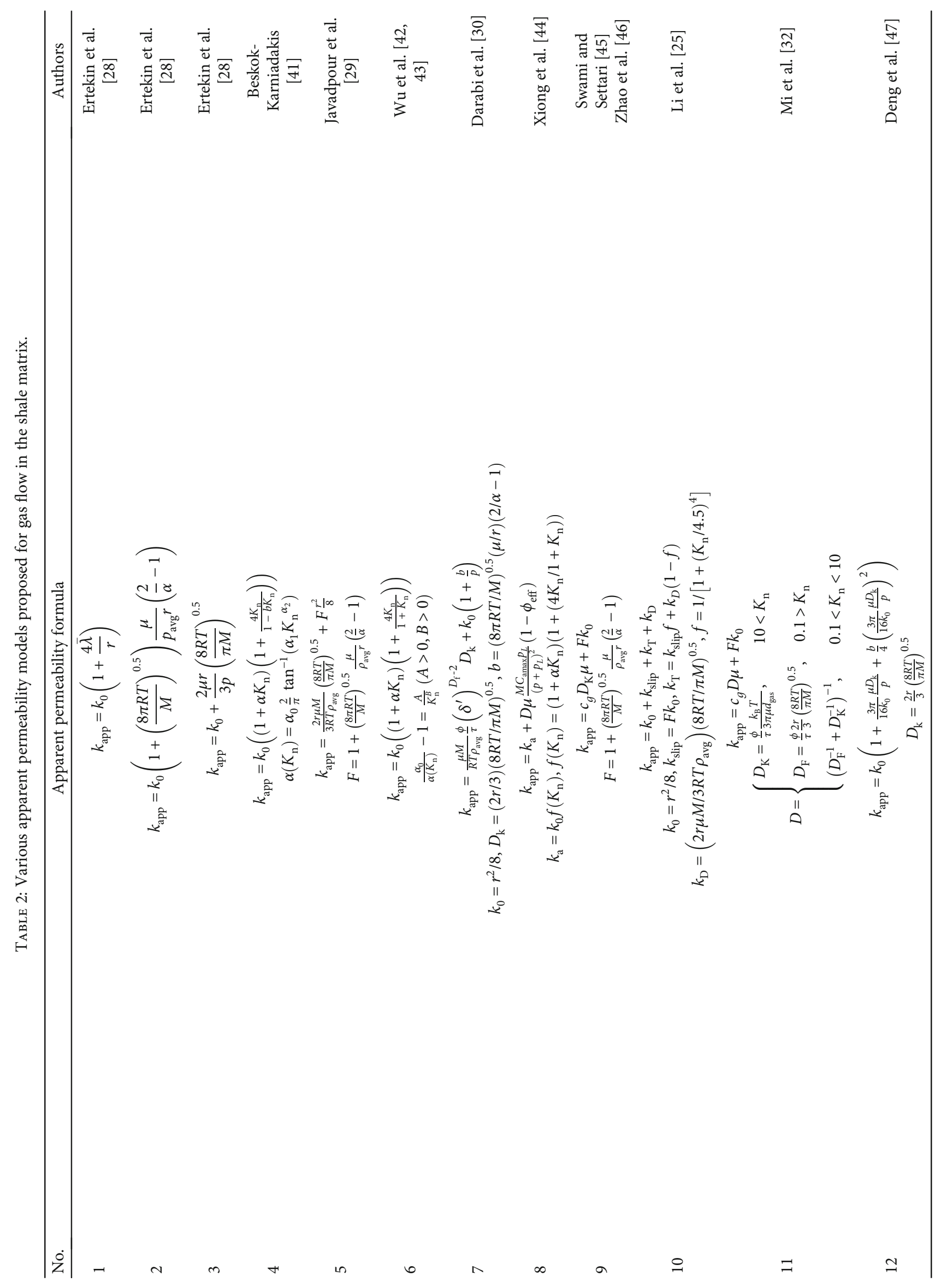




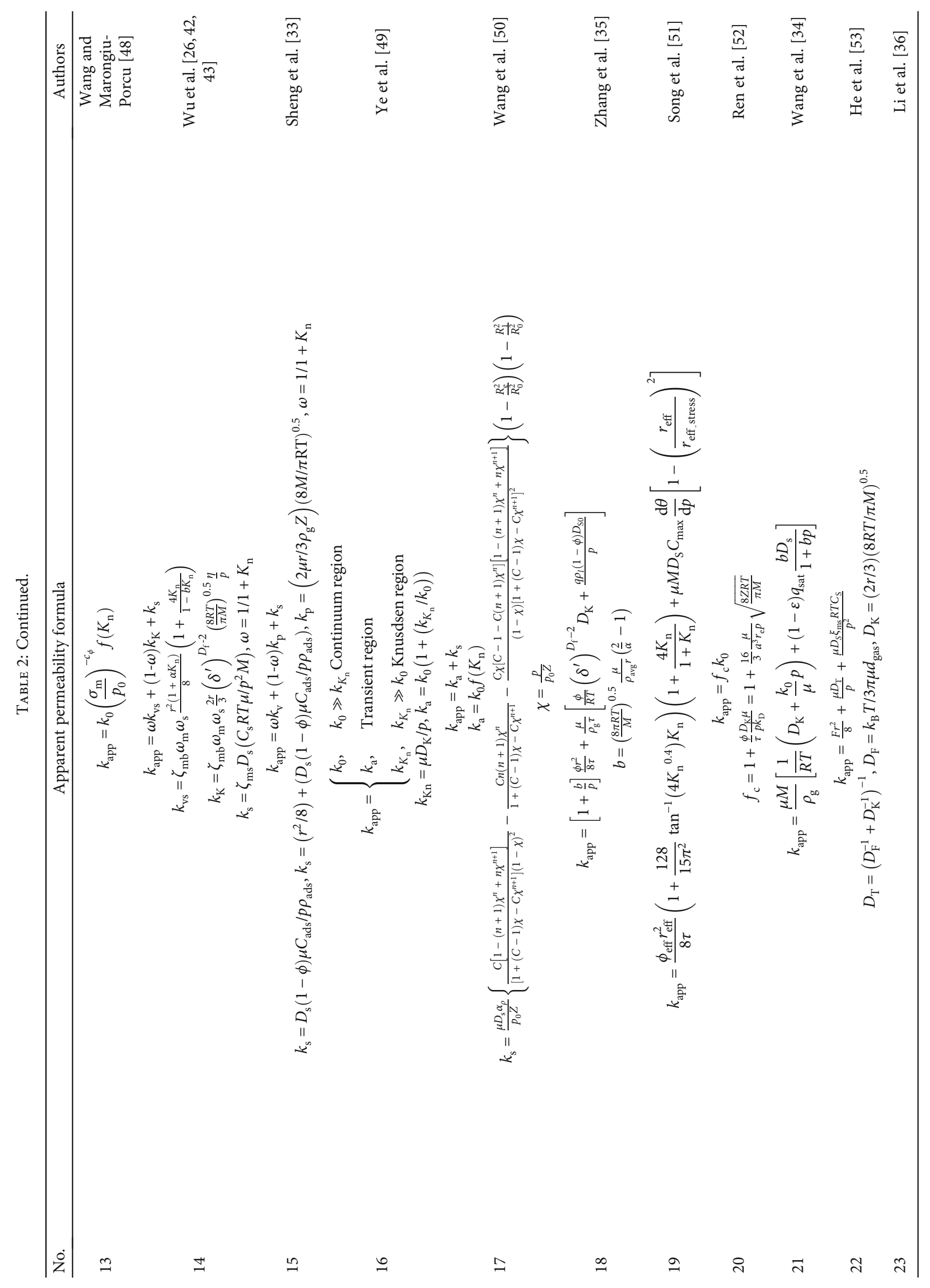




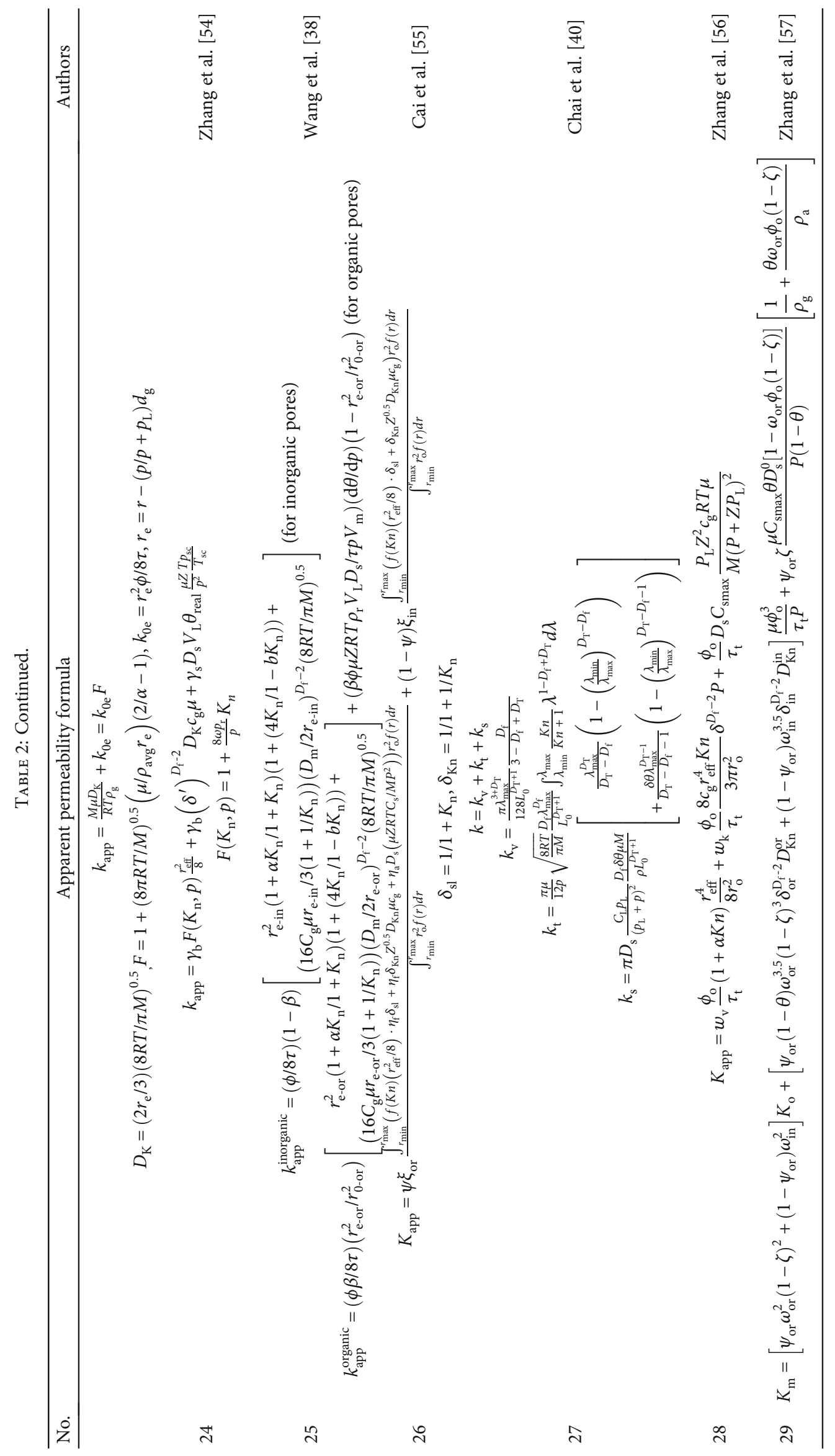


can be expressed as

$$
\theta_{\text {real }}=\frac{b p / Z}{1+b p / Z}
$$

$r_{\text {eff }}$ is the effective hydraulic radius considering the effect of stress dependence and gas adsorption on a solid surface, $\mathrm{m}$.

$$
r_{\text {eff }}=r_{0}\left[\frac{1-\left(\sigma / p_{1}\right)^{m}}{1-\left(\sigma_{0} / p_{1}\right)^{m}}\right]^{1.5}-d_{m} \theta_{\text {real }} \text {, }
$$

where $d_{\mathrm{m}}$ is the gas molecular diameter, $\mathrm{m} ; \sigma$ is the effective stress, $\mathrm{Pa} ; \sigma_{0}$ is the effective stress under initial state, $\mathrm{Pa} ; p_{1}$ and $m$ are the parameters related to the pore stiffness and roughness, respectively; $r_{0}$ is the radius of the capillary tube, m.

\section{Comprehensive Mathematical Models}

The development of natural fracture in shale gas reservoir is very rich, which makes the development of shale gas reservoirs of economic value. Therefore, there are at least two types of pores in shale reservoirs including natural fractures and nanopores in the matrix system, which are properly presented by multiple medium models. Through the review of theories and models of transient well flow, the following three types of continuum models, as shown in Figure 9, are the most widely used $[1,58]$.

To sum up, the storage spaces in shale gas reservoirs span multiple scales, from matrix nanopores to artificial fractures; free, adsorbed, and dissolved gas coexist, with most in the adsorbed state; and gas migration mechanisms include adsorption-desorption, diffusion, and seepage. Models of gas flow must account for the physical properties of the reservoir. Current shale gas seepage models consist of adsorption/desorption models (equilibrium and nonequilibrium diffusion-percolation models) and models based on the reservoir medium (dual-, triple-, and quadruple-porosity models) $[13,23,24,58-63]$. The models based on reservoir media considers the distribution of pore types and natural microfractures at different scales in the reservoir matrix, and they couple adsorption and desorption together.

The equilibrium ad/desorption-diffusion model is theoretically based and reflects physical phenomena. In this model, when reservoir pressure decreases, adsorbed gas instantly desorbs and enters macropores; the time required for gas to migrate into matrix nanopores (the desorptiondiffusion time) is not considered, i.e., the pressure of gas adsorbed on micropore walls and the pressure of free gas in macroscopic pores are in a state of continuous equilibrium. The equilibrium adsorption model is a single-porosity partial differential equation that incorporates a pressure-dependent point source term in a conventional single- or multiporosity-medium model for the adsorption and desorption characteristics of shale/coal reservoirs, or it is obtained by adding ad/desorption compressibility to the total compressibility. The partial differential equation can be solved with analytic or numerical methods [13, 65-68]. A represen- tative model of percolation was proposed by Bumb and McKee for gas seepage in coalbed methane, and this model has been widely used by other scholars [66]. Bumb and McKee used actual data to verify that desorption of coalbed methane and shale gas followed the Langmuir isotherm, and they proposed the concept of "modified ad/desorption compressibility" to consider the effect of desorption of coalbed methane during reservoir development. This concept refers to the compressibility of shale gas and shale reservoirs (the isothermal compression coefficient) and the isothermal adsorption characteristics of shale gas, which represents gas desorption. Using this method, Bumb and McKee examined the pressure response of a vertical well in a homogeneous reservoir. They concluded that although the shape of the test curve remained constant, the presence of adsorbed gas would shift the curve to the right in proportion to the quantity of adsorbed gas. Although Bumb and McKee did not consider natural fractures and only discussed the effects of adsorbed gas in homogeneous reservoir models, their method was widely used to examine seepage in coalbed and shale gas reservoirs. The model is simple to use, and the compressibility of the system can be adjusted to take into account the influence of adsorbed gas and different types of porous media on well production [65-69].

The nonequilibrium ad/desorption-diffusion model assumes that the adsorption, desorption, diffusion, and seepage of shale gas are interdependent and diffusion cannot be neglected $[17,70,71]$. Different from the equilibrium model, desorbed gas and fracture systems in the nonequilibrium adsorption-diffusion model do not reach equilibrium instantaneously but exist in dynamic equilibrium, which is described by diffusion equations. The nonequilibrium model can more accurately reflect the theoretical occurrence and migration of shale gas [27] and has been widely used for coalbed and shale gas reservoirs [17, 27, 31, 47, 70-72]. This model consists of Fick, Knudsen, and surface diffusion models. We summarize the conceptual models proposed to describe the gas flow in shale gas reservoirs by coupling different diffusion models and combinations of reservoir media, which can be divided into five types, as shown in Figure 10 [1].

4.1. Conceptual Model 1: Microfracture + Equilibrium Ad/Desorption Diffusion ("Quasi-Dual-Porosity”). The following assumptions are used for this model: the shale gas reservoirs are composed of only microfractures and matrix; adsorption and interporosity flow within the matrix are negligible; adsorbed gas only exists on the surface of matrix; and the microfractures are not only the storage space for free gas but also the main channels for desorbed gas flowing into hydraulic fractures or wellbores. The physical model is shown in Figure 10, $1[64,66,69,73,74]$.

In spherical coordinates, the continuity equation of shale gas flow in fractures is

$$
\frac{1}{r^{2}} \frac{\partial}{\partial r}\left(\frac{k_{\mathrm{f}}}{\mu_{\mathrm{g}}} \rho_{\mathrm{g}} r^{2} \frac{\partial p_{\mathrm{f}}}{\partial r}\right)=\frac{\partial\left(\phi_{\mathrm{f}} \rho_{\mathrm{g}}\right)}{\partial t}+q_{\mathrm{des}},
$$




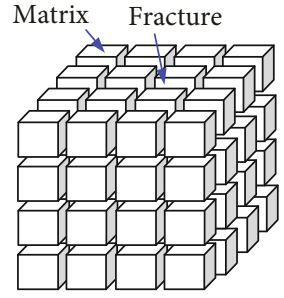

(a) Warren and Root's model

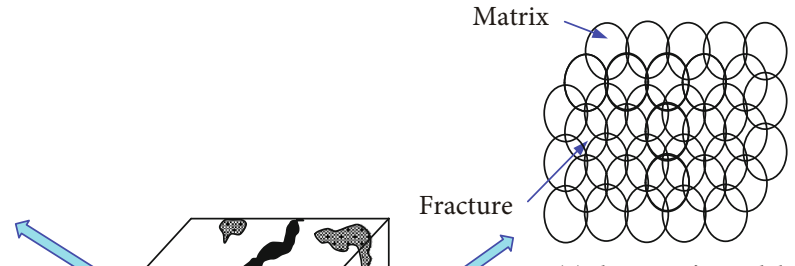

(c) de Swaan's model

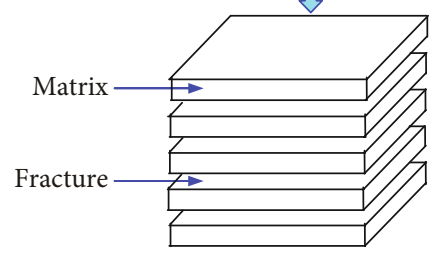

(b) Kazemi’s model

Figure 9: Conceptual model for dual-porosity formation [58-60, 64].

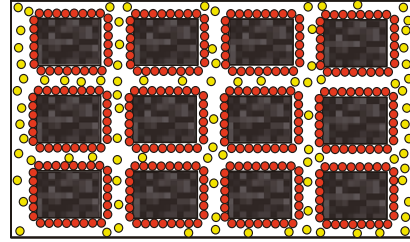

Gas flows into microfractures after desorbing from matrix

(1) Conceptual model 1

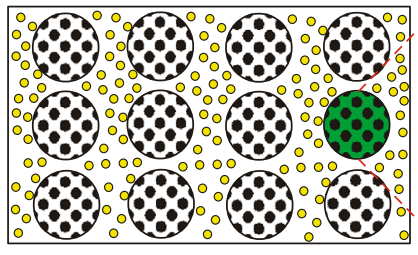

Gas desorption and diffusion from matrix elements to microfractures

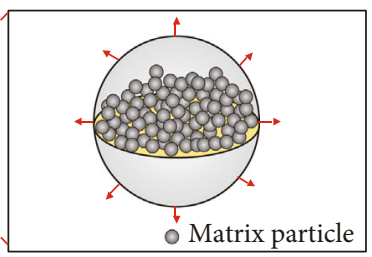

Spherical matrix element

(3) Conceptual model 3

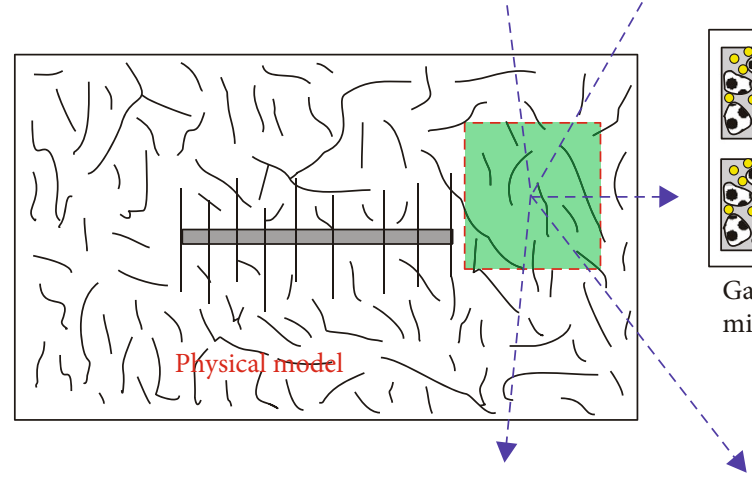

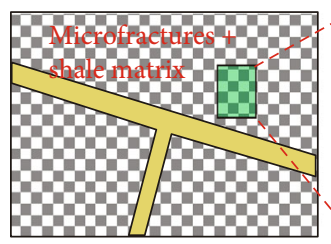

Free gas flow from macropores to microfractures

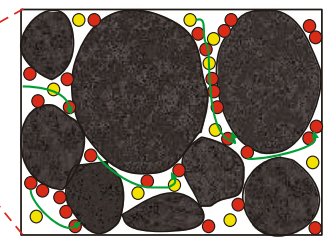

Desorbed gas flow from matrix to macropores

(2) Conceptual model 2

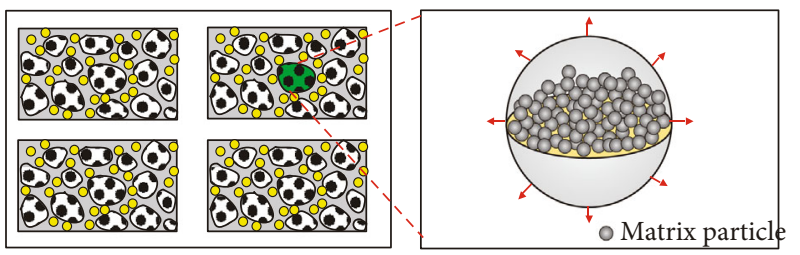

Gas flow from macropores to Gas desorption and flow from matrix microfractures

(4) Conceptual model 4

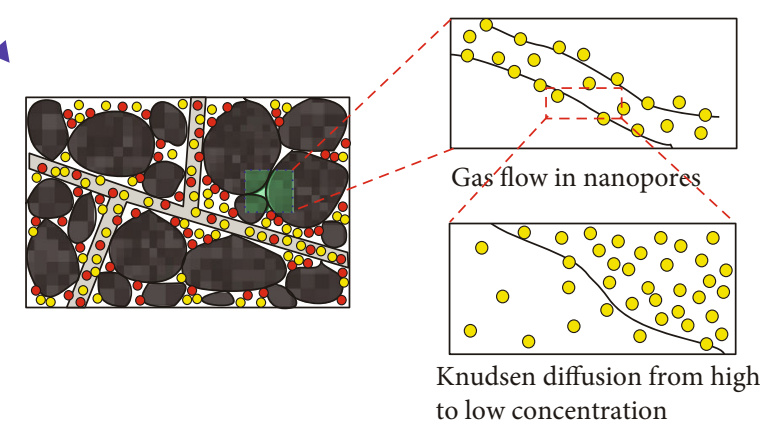

(5) Conceptual model 5

FIGURE 10: Conceptual models for gas transport mechanisms in shale gas reservoirs [1]. 
where $p_{\mathrm{f}}$ is the pressure of the microfracture system $(\mathrm{Pa}) ; \rho_{\mathrm{g}}$ is the gas density at the given conditions $\left(\mathrm{kg} / \mathrm{m}^{3}\right) ; \varnothing_{f}$ is the porosity of the microfracture system (dimensionless); $k_{\mathrm{f}}$ is the permeability of the microfracture system $\left(\mathrm{m}^{2}\right) ; q_{\text {des }}$ the is gas mass by steady-state desorption from unit reservoir volume $\left(\mathrm{kg} / \mathrm{m}^{3} \bullet \mathrm{s}\right) ; r$ is the radial coordinate $(\mathrm{m}) ; t$ is the production time (s).

For steady-state desorption and diffusion, according to Langmuir isothermal adsorption equation, we have

$$
q_{\mathrm{des}}=\rho_{\mathrm{gsc}}\left(1-\phi_{\mathrm{f}}\right) V_{\mathrm{L}} \frac{p_{\mathrm{L}}}{\left(p_{\mathrm{L}}+p_{\mathrm{f}}\right)^{2}} \frac{\partial p_{\mathrm{f}}}{\partial t},
$$

where $\rho_{g c}$ is the gas density at standard condition $\left(\mathrm{kg} / \mathrm{m}^{3}\right) ; p_{\mathrm{L}}$ is the Langmuir pressure $(\mathrm{Pa})$.

4.2. Conceptual Model 2: Microfracture + Matrix Pores + Equilibrium Ad/Desorption Diffusion ("Triporosity"). When there are a large number of macropores developing in the shale reservoir matrix, it will result in a certain error to ignore gas containing and flowing in such pores. Therefore, some scholars proposed the conceptual model of triple porosity. In the triple porosity model, the adsorbed gas on the matrix surface goes into macropores instead of microfractures after desorption and then flows into microfractures from macropores (as shown in Figure 10, 2) [1, 13, 75].

In spherical coordinates, the continuity equation of shale gas flow in fractures is

$$
\frac{1}{r^{2}} \frac{\partial}{\partial r}\left(\frac{k_{\mathrm{f}}}{\mu_{\mathrm{g}}} \rho_{\mathrm{g}} r^{2} \frac{\partial p_{\mathrm{f}}}{\partial r}\right)+q_{\mathrm{m}}=\frac{\partial\left(\phi_{\mathrm{f}} \rho_{\mathrm{g}}\right)}{\partial t},
$$

where $q_{\mathrm{m}}$ is the gas mass flow from the matrix macropores to microfractures in unit reservoir volume $\left(\mathrm{kg} / \mathrm{m}^{3} \bullet \mathrm{s}\right)$.

4.2.1. Transient Interporosity Flow Model. When gas flow from matrix to fractures is transient interporosity flow, the continuity equation of gas flow in the matrix can be expressed as

$$
\frac{1}{r_{\mathrm{m}}^{2}} \frac{\partial}{\partial r_{\mathrm{m}}}\left(\frac{k_{\mathrm{m}}}{\mu_{\mathrm{g}}} \rho_{\mathrm{g}} r_{\mathrm{m}}^{2} \frac{\partial p_{\mathrm{m}}}{\partial r_{\mathrm{m}}}\right)=\frac{\partial\left(\phi_{\mathrm{m}} \rho_{\mathrm{g}}\right)}{\partial t}+q_{\text {des }},
$$

where $k_{\mathrm{m}}$ is the permeability of shale matrix $\left(\mathrm{m}^{2}\right) ; p_{\mathrm{m}}$ is the pressure in the matrix system $(\mathrm{Pa}) ; r_{\mathrm{m}}$ is the radius in the matrix (m).

Initialization condition and corresponding boundary conditions for the spherical matrix model have been reported by de Swaan [60].

The interporosity flow rate $q_{\mathrm{m}}$ can be expressed as

$$
q_{\mathrm{m}}=-\left.\frac{3 \rho_{\mathrm{g}}}{R_{\mathrm{m}}} \frac{k_{\mathrm{m}}}{\mu_{\mathrm{g}}} \frac{\partial p_{\mathrm{m}}}{\partial r_{\mathrm{m}}}\right|_{r_{\mathrm{m}}=R_{\mathrm{m}}},
$$

where $R_{\mathrm{m}}$ is the radius of the spherical matrix element (m).
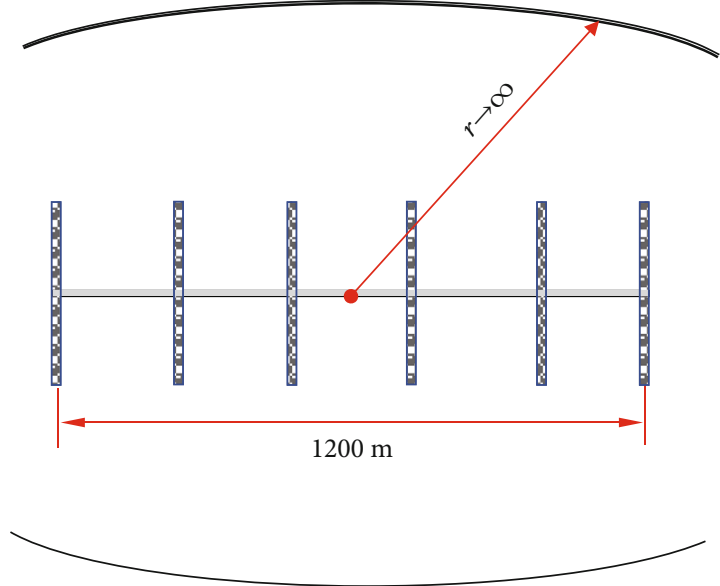

FIgURE 11: Schematic of a fractured horizontal well with infinite outer boundary.

For gas desorption rate $q_{\mathrm{des}}$, according to Langmuir isothermal equation, there is

$$
q_{\mathrm{des}}=\rho_{\mathrm{g}}\left(1-\phi_{\mathrm{f}}-\phi_{\mathrm{m}}\right) G_{\mathrm{L}} \frac{p_{\mathrm{L}}}{\left(p_{\mathrm{L}}+p_{\mathrm{m}}\right)^{2}} \frac{\partial p_{\mathrm{m}}}{\partial t} .
$$

4.2.2. Pseudo-Steady-State Flow. When gas flow from macropores to microfractures is pseudo-steady-state flow, the interporosity flow in macropores can be represented as [59]

$$
-q_{\mathrm{m}}=\frac{\partial\left(\phi_{\mathrm{m}} \rho_{\mathrm{g}}\right)}{\partial t}+q_{\mathrm{des}}
$$

Assuming the flow from the matrix to the fracture system is pseudo-steady-state flow, there is

$$
q_{\mathrm{m}}=\frac{\alpha k_{\mathrm{m}}}{\mu_{\mathrm{g}}}\left(\rho_{\mathrm{gm}} p_{\mathrm{m}}-\rho_{\mathrm{gf}} p_{\mathrm{f}}\right)
$$

where $\alpha$ is the matrix shape factor $\left(1 / \mathrm{m}^{2}\right) ; \rho_{\mathrm{gm}}$ is the gas density at matrix pressure condition $\left(\mathrm{kg} / \mathrm{m}^{3}\right) ; \rho_{\mathrm{gf}}$ is the gas density at fracture pressure condition $\left(\mathrm{kg} / \mathrm{m}^{3}\right)$.

4.3. Conceptual Model 3: Microfracture + Adsorbed Gas Desorption + Fick Diffusion in Matrix Pores. Gas diffusion is assumed as a steady state for the two models introduced above. Later on, the Fick diffusion theory was introduced to describe the desorption and diffusion of shale gas. Compared to model 1, Fick diffusion rather than steady-state diffusion is used in this model. The physical desorption and diffusion process is illustrated in Figure 10, 3 [1, 30, 76-78].

In spherical coordinates, the continuity equation of shale gas flow in fractures is

$$
\frac{1}{r^{2}} \frac{\partial}{\partial r}\left(\frac{k_{\mathrm{f}}}{\mu_{\mathrm{g}}} \rho_{\mathrm{g}} r^{2} \frac{\partial p_{\mathrm{f}}}{\partial r}\right)=\frac{\partial\left(\phi_{\mathrm{f}} \rho_{\mathrm{g}}\right)}{\partial t}+q_{\mathrm{F}}
$$


TABLE 3: Parameters used for the models.

\begin{tabular}{|c|c|c|c|}
\hline Variables & Value & Variables & Value \\
\hline Reservoir pressure, $p_{\mathrm{i}}(\mathrm{MPa})$ & 25 & Reservoir temperature, $T(\mathrm{~K})$ & 320 \\
\hline Formation thickness, $h(\mathrm{~m})$ & 60 & Fracture half length, $x_{\mathrm{f}}(\mathrm{m})$ & 30 \\
\hline Gas-specific gravity, $\gamma_{\mathrm{g}}$ (fraction) & 0.65 & Well production rate, $q_{\mathrm{sc}}\left(\mathrm{m}^{3} / \mathrm{d}\right)$ & $1 \times 10^{4}$ \\
\hline Langmuir pressure, $P_{\mathrm{L}}(\mathrm{MPa})$ & 4 & Langmuir volume, $G_{\mathrm{L}}\left(\mathrm{m}^{3} / \mathrm{m}^{3}\right)$ & 10 \\
\hline Skin factor, $S_{\text {kin }}$ (dimensionless) & 0.1 & Dimensionless wellbore storage, $C_{\mathrm{D}}$ & $10^{-6}$ \\
\hline Number of fracture, $M$ & 6 & Horizontal well length, $L(\mathrm{~m})$ & 1200 \\
\hline \multicolumn{4}{|l|}{ Conceptual model 1} \\
\hline Permeability of natural fractures, $k_{\mathrm{f}}(\mathrm{mD})$ & 0.01 & Porosity of natural fractures, $\varnothing_{f}$ (fraction) & 0.02 \\
\hline \multicolumn{4}{|l|}{ Conceptual model 2} \\
\hline Permeability of natural fractures, $k_{\mathrm{f}}(\mathrm{mD})$ & 0.01 & Porosity of natural fractures, $\varnothing_{f}$ (fraction) & 0.02 \\
\hline Permeability of macropores, $k_{\mathrm{m}}(\mathrm{mD})$ & 0.0001 & Porosity of macropores, $\varnothing_{m}$ & 0.12 \\
\hline Shape factor, $\alpha\left(1 / \mathrm{m}^{2}\right)$ & $10^{-5}$ & & \\
\hline \multicolumn{4}{|l|}{ Conceptual model 3} \\
\hline Permeability of natural fractures, $k_{\mathrm{f}}(\mathrm{mD})$ & 0.01 & Porosity of natural fractures, $\varnothing_{f}$ (fraction) & 0.02 \\
\hline Well production rate, $q_{\mathrm{sc}}\left(\mathrm{m}^{3} / \mathrm{d}\right)$ & $1 \times 10^{4}$ & $\left(R_{\mathrm{m}}\right)^{2} / D_{\mathrm{F}}$ & $2 \times 10^{6}$ \\
\hline \multicolumn{4}{|l|}{ Conceptual model 4} \\
\hline Permeability of natural fractures, $k_{\mathrm{f}}(\mathrm{mD})$ & 0.01 & Porosity of natural fractures, $\varnothing_{f}$ (fraction) & 0.02 \\
\hline Permeability of macropores, $k_{\mathrm{m}}(\mathrm{mD})$ & 0.0001 & Porosity of macropores, $\varnothing_{m}$ & 0.12 \\
\hline Well production rate, $q_{\mathrm{sc}}\left(\mathrm{m}^{3} / \mathrm{d}\right)$ & $1 \times 10^{4}$ & $\left(R_{\mathrm{m}}\right)^{2} / D_{\mathrm{F}}$ & $2 \times 10^{6}$ \\
\hline Shape factor, $\alpha\left(1 / \mathrm{m}^{2}\right)$ & $10^{-5}$ & & \\
\hline \multicolumn{4}{|l|}{ Conceptual model 5} \\
\hline Permeability of natural fractures, $k_{\mathrm{f}}(\mathrm{mD})$ & 0.01 & Porosity of natural fractures, $\varnothing_{f}$ (fraction) & 0.02 \\
\hline Permeability of matrix, $k_{\mathrm{m}}(\mathrm{mD})$ & 0.0001 & Porosity of matrix, $\varnothing_{m}$ & 0.12 \\
\hline Shape factor, $\alpha\left(1 / \mathrm{m}^{2}\right)$ & $10^{-5}$ & Knudsen diffusion coefficient, $D_{\mathrm{k}}\left(1 / \mathrm{m}^{2}\right)$ & $10^{-6}$ \\
\hline
\end{tabular}

In unit reservoir volume, the diffusion of gas from matrix to fractures is

$$
q_{\mathrm{F}}=M_{\mathrm{g}}\left(1-\phi_{\mathrm{f}}\right) \frac{d C_{\mathrm{m}}}{d t} .
$$

For pseudo-steady-state and unsteady-state gas diffusion from matrix to fractures, there is

$\frac{d C_{\mathrm{m}}}{d t}= \begin{cases}\left.\frac{3 D_{\mathrm{F}}}{R_{\mathrm{m}}} \frac{\partial C_{\mathrm{m}}}{\partial r_{\mathrm{m}}}\right|_{r_{\mathrm{m}}=R_{\mathrm{m}}} & \text { unsteady-state diffusion, } \\ \frac{6 D_{\mathrm{F}} \pi^{2}}{R_{\mathrm{m}}^{2}}\left[C_{\mathrm{E}}\left(p_{\mathrm{f}}\right)-C_{\mathrm{m}}\right] & \text { pseudo-steady-state diffusion, }\end{cases}$

where $D_{\mathrm{F}}$ is the Fick diffusion coefficient $\left(\mathrm{m}^{2} / \mathrm{s}\right) ; R_{\mathrm{m}}$ is the radius of spherical matrix element $(\mathrm{m}) ; C_{\mathrm{E}}$ is the gas molar concentration when the gas adsorption at the matrix surface is in equilibrium with free gas in microfractures $\left(\mathrm{mol} / \mathrm{m}^{3}\right)$.

For Fick diffusion, the following mathematical expression can be used to describe gas concentration change in matrix.

$$
\frac{\partial C_{\mathrm{m}}}{\partial t}=\frac{1}{r_{\mathrm{m}}^{2}} \frac{\partial}{\partial r_{\mathrm{m}}}\left(D r_{\mathrm{m}}^{2} \frac{\partial C_{\mathrm{m}}}{\partial r_{\mathrm{m}}}\right),
$$

where $C_{\mathrm{m}}$ is the shale gas volume concentration in matrix under unsteady state $\left(\mathrm{mol} / \mathrm{m}^{3}\right) ; r_{\mathrm{m}}$ is the inner diameter of sphere matrix element $(\mathrm{m})$.

4.4. Conceptual Model 4: Microfracture + Matrix Macropores + Adsorbed Gas Desorption + Fick Diffusion in Nanopores. Similar to the steady-state diffusion model, if the macropores are well developed in shale matrix, desorption gas is assumed to flow into macropores and then into microfractures. This model is first proposed by us, and the physical process is shown in Figure 10, 4.

In spherical coordinates, the continuity equation of shale gas flow in the fractures is

$$
\frac{1}{r^{2}} \frac{\partial}{\partial r}\left(\frac{k_{\mathrm{f}}}{\mu_{\mathrm{g}}} \rho_{\mathrm{g}} r^{2} \frac{\partial p_{\mathrm{f}}}{\partial r}\right)+q_{\mathrm{m}}=\frac{\partial\left(\phi_{\mathrm{f}} \rho_{\mathrm{g}}\right)}{\partial t} .
$$

(1) For transient interporosity flow from matrix to fractures, the continuity equation for flow in matrix is

$$
\frac{1}{r_{\mathrm{m}}^{2}} \frac{\partial}{\partial r_{\mathrm{m}}}\left(\frac{k_{\mathrm{m}}}{\mu_{\mathrm{g}}} \rho_{\mathrm{g}} r_{\mathrm{m}}^{2} \frac{\partial p_{\mathrm{m}}}{\partial r_{\mathrm{m}}}\right)=\frac{\partial\left(\phi_{\mathrm{m}} \rho_{\mathrm{g}}\right)}{\partial t}+q_{\mathrm{F}} .
$$




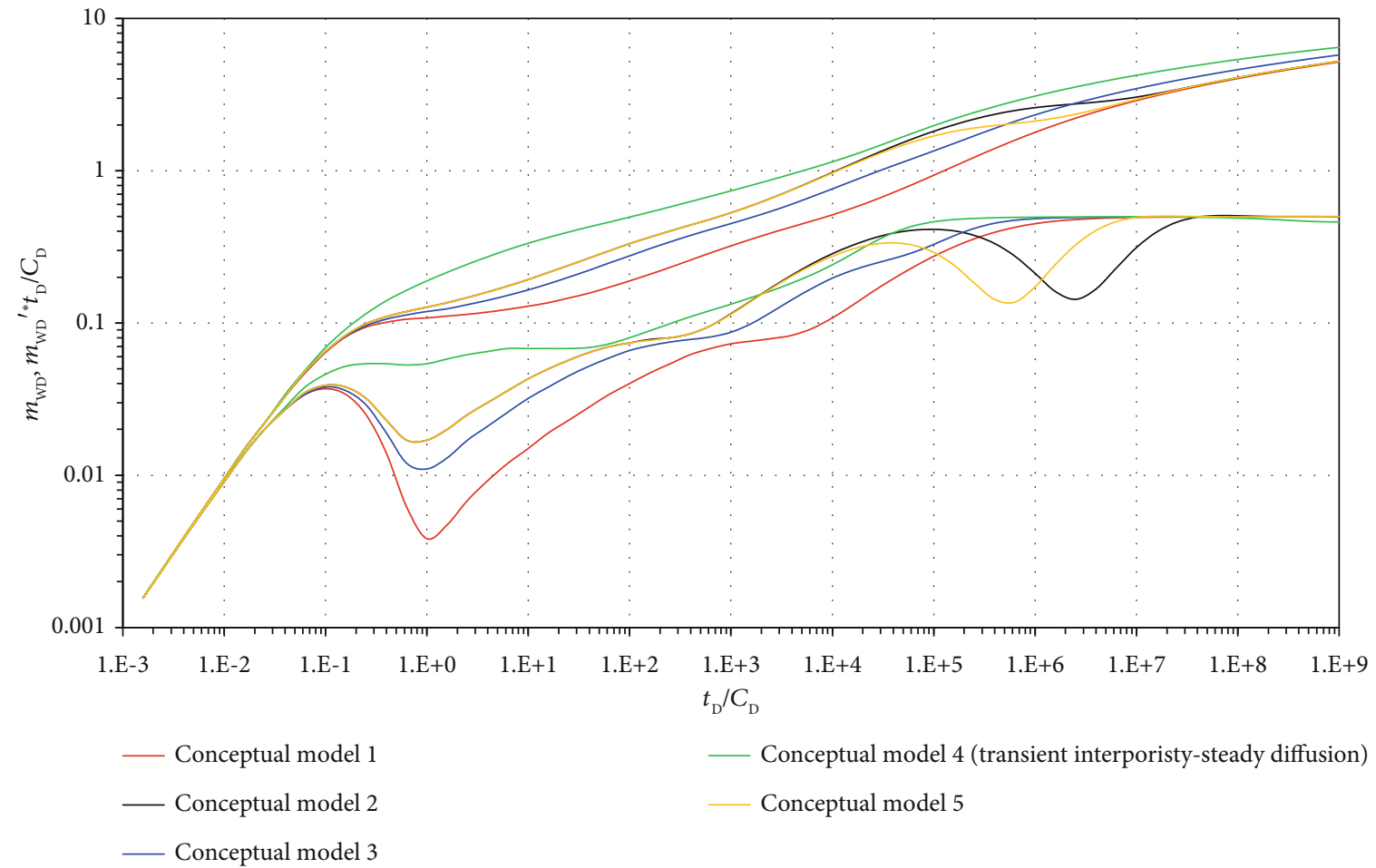

Figure 12: Type curves of fractured horizontal well with different conceptual models.

For unsteady-state flow from macropores to fractures, the flow rate $q_{\mathrm{m}}$ has a similar expression as Equation (12), and the diffusion rate caused by Fick diffusion $q_{\mathrm{F}}$ can be expressed as

$$
q_{\mathrm{F}}=M_{\mathrm{g}}\left(1-\phi_{\mathrm{f}}\right)\left(1-\phi_{\mathrm{m}}\right) \frac{\mathrm{d} C_{\mathrm{m}}}{\mathrm{d} t}
$$

(2) For pseudo-steady-state flow from macropores to microfractures, the continuity equation for flow in macropores is

$$
-q_{\mathrm{m}}=\frac{\partial\left(\phi_{\mathrm{m}} \rho_{\mathrm{g}}\right)}{\partial t}+q_{\mathrm{F}}
$$

where $q_{\mathrm{m}}$ has a similar expression as Equation (15)

4.5. Conceptual Model 5: Microfracture + Adsorbed Gas Desorption + Knudsen Diffusion in Nanopore Models. In recent years, the Knudsen diffusion model has been widely used to describe the gas flow process in nanopores. Most of the researchers thought that gas flow in shale nanopores is a kind of complex flow under the combined influence of multiple mechanisms, e.g., slippage effect, Darcy flow, Knudsen diffusion, and adsorption-desorption [1, 3, 17, 31, 59, 7981]. The physical model of microscopic gas flow in shale reservoirs is shown in Figure 10, 5.
Since gas flow in the microfracture system follows Darcy's Law, the continuity equation is similar to those of previous models and can be expressed in spherical coordinates as [31]

$$
\frac{1}{r^{2}} \frac{\partial}{\partial r}\left(\frac{k_{\mathrm{f}}}{\mu_{\mathrm{g}}} \rho_{\mathrm{g}} r^{2} \frac{\partial p_{\mathrm{f}}}{\partial r}\right)+q_{\mathrm{m}}=\frac{\partial\left(\phi_{\mathrm{f}} \rho_{\mathrm{g}}\right)}{\partial t}
$$

(1) For transient interporosity flow from matrix to fractures, the continuity equation of flow in matrix is

$$
\frac{1}{r_{\mathrm{m}}^{2}} \frac{\partial}{\partial r_{\mathrm{m}}}\left(\frac{k_{\mathrm{app}}}{\mu_{\mathrm{g}}} \rho_{\mathrm{g}} r_{\mathrm{m}}^{2} \frac{\partial p_{\mathrm{m}}}{\partial r_{\mathrm{m}}}\right)=\frac{\partial\left(\phi_{\mathrm{m}} \rho_{\mathrm{g}}\right)}{\partial t}+q_{\mathrm{des}}
$$

(2) For the pseudo-steady-state flow from macropores to microfractures, the continuity equation of flow in macropores is

$$
-q_{\mathrm{m}}=\frac{\partial\left(\phi_{\mathrm{m}} \rho_{\mathrm{g}}\right)}{\partial t}+q_{\mathrm{des}}
$$

In order to compare the effects of different conceptual models on type curves of fractured horizontal well in shale 
gas reservoirs, there is a horizontal well with a length of $1200 \mathrm{~m}$ located at the center of a shale gas reservoir with infinite outer boundary (as shown in Figure 11). Six hydraulic fractures are uniformly distributed along the horizontal well. The essential parameters and some unique parameters for each model are listed in Table 3. For such models, the semianalytical solutions can be easily derived by the source function idea and superposition theory, which has been reported and used to analyze the well production performance of complex structure wells, such as horizontal well, slanted well, fractured vertical well, and fractured horizontal well. Figure $12 \mathrm{com}-$ pares the type curves of fractured horizontal well in shale gas reservoirs with different conceptual models. It can clearly see that the models mainly affect the early flow periods and the interporosity flow period during the gas flow from matrix pores into natural fractures. Here, we just list a set of type curves in Figure 12 for the physical models in Figure 11. Due to the consideration of different flow mechanisms or different pore types, the type curves have different characteristics. For model 1, adsorption and interporosity flow within the matrix are negligible, and the only flow channels are microfractures with high seepage capacity, so it is relatively easy to maintain the gas supply to the well, resulting in the most concave type curves among 5 curves of dimensionless pseudopressure derivative. Compared with model 2 , model 5 considers the Knudsen diffusion effect in nanopores, which is equivalent to increasing the gas supply, so the concave of dimensionless pseudopressure derivative appears earlier before the boundary control flow stage. And there are many models that have been proposed, such as the liner flow model, discrete fracture models, and fractured horizontal well in different outer boundaries, so the readers can utilize the models presented in this paper to analyze the well production performance of different models. Besides, the conceptual model can also be considered in the numerical simulation [82-85].

\section{Conclusions}

This paper presents a comprehensive review for gas flow and the mathematical models of gas transport in multiscaled shale gas reservoir, which can be easily used to the well testing and flow performance analysis of wells in shale gas reservoirs by combing them with the well models.

The reported apparent permeability models are summarized firstly. Until now, there is no unified model that can be reliable and acceptable in the petroleum industry. Most expressions of apparent permeability are constructed by coupling slippage flow formula with the Knudsen diffusion formula with different weighting coefficient. For this method, the choice of weighting coefficient is always controversial.

Five comprehensive models are established under the assumption of a continuum medium model and single gas flow. Model 1 and model 2 are established under the equilibrium adsorption-diffusion model, model 1 does not consider the gas flow in the matrix system, and model 2 divides the formation into a natural fracture system and matrix macropore system. Model 3 is the classical transport model used in coalbed, which also divides the pores into two types. Different from model 2, model 3 considers the gas transport in matrix pores by Fick diffusion. We proposed model 4, which divides the matrix pores into macro ores and nanopores, and the gas flow in nanopores follows Fick diffusion and in macropores follows conventional viscous flow. Model 5 is most widely used recently, which introduces an apparent permeability to take into account the complex transport mechanisms in shale matrix, including viscous flow, slippage flow, Knudsen flow, and surface flow.

Although many achievements have been made in the mechanism of shale gas seepage, most researches are carried out in the microscale. The application of shale gas complex transport mechanisms in numerical simulation and other fields is rare and needs to be studied urgently.

\section{Conflicts of Interest}

The authors declare that they have no conflicts of interest.

\section{Acknowledgments}

This work was supported by the National Natural Science Foundation of China (Key Program) (Grant No. 51534006), the National Natural Science Foundation of China (Grant Nos. 51874251 and 51704247), and the PetroChina Innovation Foundation (No. 2018D-5007-0218).

\section{References}

[1] L. Zhang, Z. Chen, and Y. Zhao, Well Production Performance Analysis for Shale Gas Reservoirs, Elsevier, Cambridge, United States, 2019.

[2] J. B. Curtis, "Fractured shale-gas systems," AAPG Bulletin, vol. 86, 2002.

[3] Y. Zhao, L. Zhang, and B. Shan, "Mathematical model of fractured horizontal well in shale gas reservoir with rectangular stimulated reservoir volume," Journal of Natural Gas Science and Engineering, vol. 59, pp. 67-79, 2018.

[4] Y. Zhao, X. Tang, L. Zhang, H. Tang, and Z. Tao, "Numerical solution of fractured horizontal wells in shale gas reservoirs considering multiple transport mechanisms," Journal of Geophysics and Engineering, vol. 15, no. 3, pp. 739-750, 2018.

[5] Y. Mei-Juan, Y. Bo-Ming, X. Peng, and C. Jian-Chao, "Fractal analysis of power-law fluid in a single capillary," Chinese Physics Letters, vol. 25, no. 2, pp. 616-619, 2008.

[6] J. He, J. Wang, Q. Yu et al., "Pore structure of shale and its effects on gas storage and transmission capacity in well HD-1 eastern Sichuan Basin, China," Fuel, vol. 226, pp. 709-720, 2018.

[7] K. Liu, M. Ostadhassan, J. Zou et al., "Nanopore structures of isolated kerogen and bulk shale in Bakken Formation," Fuel, vol. 226, pp. 441-453, 2018.

[8] C. Cipolla, E. Lolon, J. Erdle, and B. Rubin, "Reservoir modeling in shale-gas reservoirs," SPE Reservoir Evaluation \& Engineering, vol. 13, no. 4, pp. 638-653, 2013.

[9] J. Yao, H. Sun, D. Fan, C. Wang, and Z. Sun, "Numerical simulation of gas transport mechanisms in tight shale gas reservoirs," Petroleum Science, vol. 10, no. 4, pp. 528-537, 2013.

[10] S. Kang, E. Fathi, R. Ambrose, I. Akkutlu, and R. Sigal, "Carbon dioxide storage capacity of organic-rich shales," SPE Journal, vol. 16, no. 4, pp. 842-855, 2013. 
[11] J. Hudson, F. Civan, G. Michel, D. Devegowda, and R. Sigal, "Modeling multiple-porosity transport in gas-bearing shale formations," in SPE Latin America and Caribbean Petroleum Engineering Conference, Mexico City, Mexico, April, 2012.

[12] M. Curtis, R. Ambrose, C. Sondergeld, and C. Rai, “Transmission and scanning electron microscopy investigation of pore connectivity of gas shales on the nanoscale," in Proceedings of the North American Unconventional Gas Conference and Exhibition, The Woodlands, Texas, USA, June, 2011.

[13] Y. Zhao, L. Zhang, J. Zhao, J. Luo, and B. Zhang, ““Triple porosity" modeling of transient well test and rate decline analysis for multi-fractured horizontal well in shale gas reservoirs," Journal of Petroleum Science \& Engineering, vol. 110, pp. 253262, 2013.

[14] K. Bowker, "Barnett shale gas production, Fort Worth Basin: issues and discussion," AAPG Bulletin, vol. 91, no. 4, pp. 523-533, 2007.

[15] M. Brittenham, "Unconventional discovery thinking in resource plays: Haynesville/Bossier trend, north Louisiana," Houston Geological Society Bulletin, vol. 53, no. 2, pp. 27-29, 2010.

[16] D. Ross and R. Bustin, "Shale gas potential of the Lower Jurassic Gordondale Member, northeastern British Columbia, Canada," Bulletin of Canadian Petroleum Geology, vol. 55, no. 1, pp. 51-75, 2007.

[17] F. Javadpour, "Nanopores and apparent permeability of gas flow in mudrocks (shales and siltstone)," Journal of Canadian Petroleum Technology, vol. 48, no. 8, pp. 16-21, 2013.

[18] E. Umeozor and I. Gates, "Predictive modeling of energy and emissions from shale gas development," Environmental Science \& Technology, vol. 52, no. 24, pp. 14547-14555, 2018.

[19] G. Chen, D. Dong, and S. Wang, "A preliminary study on accumulation mechanism and enrichment pattern of shale gas," Natural Gas Industry, vol. 29, pp. 17-21, 2009.

[20] G. King, "Material-balance techniques for coal-seam and Devonian shale gas reservoirs with limited water influx," SPE Reservoir Engineering, vol. 8, no. 1, pp. 67-72, 2013.

[21] E. Ozkan, R. Raghavan, and O. Apaydin, "Modeling of fluid transfer from shale matrix to fracture network," in In Proceedings of the SPE Annual Technical Conference and Exhibition, Florence, Italy, September 2010.

[22] T. Zhang, G. S. Ellis, S. C. Ruppel, K. Milliken, and R. Yang, "Effect of organic-matter type and thermal maturity on methane adsorption in shale-gas systems," Organic Geochemistry, vol. 47, pp. 120-131, 2012.

[23] G. Moridis and C. Freeman, "The RealGas and RealGasH2O options of the TOUGH + code for the simulation of coupled fluid and heat flow in tight/shale gas systems," Computers \& Geosciences, vol. 65, pp. 56-71, 2014.

[24] E. Ozkan, M. Brown, R. Raghavan, and H. Kazemi, “Comparison of fractured horizontal-well performance in conventional and unconventional reservoirs," Dermatologic Surgery, vol. 27, pp. 703-708, 2009.

[25] Y. Li, X. Li, J. Shi, H. Wang, and L. Wu, "A nano-pore scale gas flow model for shale gas reservoir," in Proceedings of the SPE Biennial Energy Resources Conference, Port of Spain, Trinidad and Tobago, June 2014.

[26] K. Wu, X. Li, C. Wang, Z. Chen, and W. Yu, "A model for gas transport in microfractures of shale and tight gas reservoirs," AICHE Journal, vol. 61, no. 6, pp. 2079-2088, 2015.
[27] S. Roy, R. Raju, H. Chuang, B. Cruden, and M. Meyyappan, "Modeling gas flow through microchannels and nanopores," Journal of Applied Physics, vol. 93, no. 8, pp. 4870-4879, 2003.

[28] T. Ertekin, G. King, and F. Schwerer, "Dynamic gas slippage: a unique dual-mechanism approach to the flow of gas in tight formations," SPE Formation Evaluation, vol. 1, no. 1, pp. 4352, 2013.

[29] F. Javadpour, D. Fisher, and M. Unsworth, "Nanoscale gas flow in shale gas sediments," Journal of Canadian Petroleum Technology, vol. 46, no. 10, pp. 55-61, 2007.

[30] H. Darabi, A. Ettehad, F. Javadpour, and K. Sepehrnoori, "Gas flow in ultra-tight shale strata," Journal of Fluid Mechanics, vol. 710, pp. 641-658, 2012.

[31] V. Shabro, C. Torres-Verdin, and F. Javadpour, "Pore-scale quantification of apparent permeability and electrical resistivity of hydrocarbon-bearing shale in the presence of gas desorption," in Proceedings of the SPWLA 52nd Annual Logging Symposium, Colorado Springs, Co. USA, May 2011.

[32] L. Mi, H. Jiang, J. Li, and Y. Tian, "Mathematical characterization of permeability in shale reservoirs," Journal of Petroleum, vol. 35, pp. 928-934, 2014.

[33] M. Sheng, G. Li, Z. Huang, S. Tian, S. Shah, and L. Geng, "Pore-scale modeling and analysis of surface diffusion effects on shale-gas flow in kerogen pores," Journal of Natural Gas Science and Engineering, vol. 27, pp. 979-985, 2015.

[34] J. Wang, L. Chen, Q. Kang, and S. S. Rahman, “Apparent permeability prediction of organic shale with generalized lattice Boltzmann model considering surface diffusion effect," Fuel, vol. 181, pp. 478-490, 2016.

[35] L. Zhang, D. Li, D. Lu, and T. Zhang, "A new formulation of apparent permeability for gas transport in shale," Journal of Natural Gas Science and Engineering, vol. 23, pp. 221-226, 2015.

[36] Y. Li, X. Liu, Z. Hu, S. Gao, X. Rui, and J. Chang, "A new coupling method for shale gas slippage and diffusion transport mechanism," Acta Physica Sinica, vol. 66, p. 114702, 2017.

[37] Y. Wang, S. Liu, and Y. Zhao, "Modeling of permeability for ultra-tight coal and shale matrix: a multi-mechanistic flow approach," Fuel, vol. 232, pp. 60-70, 2018.

[38] S. Wang, J. Shi, K. Wang, Z. Sun, Y. Miao, and C. Hou, "Apparent permeability model for gas transport in shale reservoirs with nano-scale porous media," Journal of Natural Gas Science and Engineering, vol. 55, pp. 508-519, 2018.

[39] J. Cai, D. Lin, H. Singh, S. Zhou, Q. Meng, and Q. Zhang, “A simple permeability model for shale gas and key insights on relative importance of various transport mechanisms," Fuel, vol. 252, pp. 210-219, 2019.

[40] D. Chai, Z. Fan, and X. Li, "A new unified gas-transport model for gas flow in nanoscale porous media," SPE Journal, vol. 24, no. 2, pp. 698-719, 2019.

[41] A. Beskok and G. Karniadakis, "A model for flows in channels, pipes, and ducts at micro and nano scales," Microscale Thermophysical Engineering, vol. 3, no. 1, pp. 43-77, 1999.

[42] K. Wu, X. Li, C. Guo, C. Wang, and Z. Chen, “A unified model for gas transfer in nanopores of shale-gas reservoirs: coupling pore diffusion and surface diffusion," SPE Journal, vol. 21, no. 5, pp. 1583-1611, 2016.

[43] K. Wu, Z. Chen, X. Li, C. Guo, and M. Wei, "A model for multiple transport mechanisms through nanopores of shale gas reservoirs with real gas effect-adsorption-mechanic coupling," 
International Journal of Heat and Mass Transfer, vol. 93, pp. 408-426, 2016.

[44] X. Xiong, D. Devegowda, G. G. Michel, R. F. Sigal, and F. Civan, "A fully-coupled free and adsorptive phase transport model for shale gas reservoirs including non-Darcy flow effects," in Proceedings of the SPE Annual Technical Conference and Exhibition, San Antonio, Texas, USA, October 2012.

[45] V. Swami and A. Settari, "A pore scale gas flow model for shale gas reservoir," in Proceedings of the Americas Unconventional Resources Conference, Pittsburgh, Pennsylvania, USA, June, 2012.

[46] Y. Zhao, L. Zhang, Y. Xiong, Y. Zhou, Q. Liu, and D. Chen, "Pressure response and production performance for multifractured horizontal wells with complex seepage mechanism in box-shaped shale gas reservoir," Journal of Natural Gas Science and Engineering, vol. 32, pp. 66-80, 2016.

[47] J. Deng, W. Zhu, and Q. Ma, "A new seepage model for shale gas reservoir and productivity analysis of fractured well," Fuel, vol. 124, pp. 232-240, 2014.

[48] H. Wang and M. Marongiu-Porcu, "Impact of shale-gas apparent permeability on production: combined effects of non-Darcy flow/gas-slippage, desorption, and geomechanics," SPE Reservoir Evaluation \& Engineering, vol. 18, no. 4, pp. 495-507, 2016.

[49] Z. Ye, D. Chen, and Z. Pan, "A unified method to evaluate shale gas flow behaviours in different flow regions," Journal of Natural Gas Science and Engineering, vol. 26, pp. 205-215, 2015.

[50] J. Wang, H. Liu, L. Wang, H. Zhang, H. Luo, and Y. Gao, "Apparent permeability for gas transport in nanopores of organic shale reservoirs including multiple effects," International Journal of Coal Geology, vol. 152, pp. 50-62, 2015.

[51] W. Song, J. Yao, Y. Li et al., "Apparent gas permeability in an organic-rich shale reservoir,” Fuel, vol. 181, pp. 973-984, 2016.

[52] W. Ren, G. Li, S. Tian, M. Sheng, and X. Fan, “An analytical model for real gas flow in shale nanopores with non-circular cross-section," AICHE Journal, vol. 62, no. 8, pp. 2893-2901, 2016.

[53] Y. He, J. Cheng, X. Dou, and X. Wang, "Research on shale gas transportation and apparent permeability in nanopores," Journal of Natural Gas Science and Engineering, vol. 38, pp. 450457, 2017.

[54] L. Zhang, B. Shan, Y. Zhao, J. Du, J. Chen, and X. Tao, "Gas transport model in organic shale nanopores considering Langmuir slip conditions and diffusion: pore confinement, real gas, and geomechanical effects," Energies, vol. 11, no. 1, p. 223, 2018.

[55] J. Cai, D. Lin, H. Singh, W. Wei, and S. Zhou, "Shale gas transport model in 3D fractal porous media with variable pore sizes," Marine and Petroleum Geology, vol. 98, pp. 437-447, 2018.

[56] L. Zhang, H. Liang, Y. Zhao, J. Xie, X. Peng, and Q. Li, “Gas transport characteristics in shale matrix based on multiple mechanisms," Chemical Engineering Journal, vol. 386, p. 124002, 2020.

[57] Q. Zhang, Y. Su, W. Wang, M. Lu, and G. Sheng, "Gas transport behaviors in shale nanopores based on multiple mechanisms and macroscale modeling," International Journal of Heat and Mass Transfer, vol. 125, pp. 845-857, 2018.

[58] J. Warren and P. Root, "The behavior of naturally fractured reservoirs," Society of Petroleum Engineers Journal, vol. 3, no. 3, pp. 245-255, 2013.
[59] H. Kazemi, "Pressure transient analysis of naturally fractured reservoirs with uniform fracture distribution," Society of Petroleum Engineers Journal, vol. 9, no. 4, pp. 451-462, 2013.

[60] A. de Swaan, "Influence of shape and skin of matrix-rock blocks on pressure transients in fractured reservoirs," SPE Formation Evaluation, vol. 5, no. 4, pp. 344-352, 2013.

[61] R. O. Bello and R. A. Wattenbarger, "Multistage hydraulically fractured horizontal shale gas well rate transient analysis," in Proceedings of the North Africa Technical Conference and Exhibition, Cairo, Egypt, February, 2010.

[62] H. A. Al-Ahmadi and R. A. Wattenbarger, "Triple-porosity models: one further step towards capturing fractured reservoirs heterogeneity," in Proceedings of the SPE/DGS Saudi Arabia Section Technical Symposium and Exhibition, Al-Khobar, Saudi Arabia, May, 2011.

[63] V. Tivayanonda, Comparison of single, double, and triple linear flow models for shale gas/oil reservoirs, Diss. Texas A\&M University, 2012.

[64] B. Xu, M. Haghighi, X. Li, and D. Cooke, "Development of new type curves for production analysis in naturally fractured shale gas/tight gas reservoirs," Journal of Petroleum Science \& Engineering, vol. 105, pp. 107-115, 2013.

[65] Z. Xu and S. Guo, "Application of NMR and X-CT technology in the pore structure study of shale gas reservoirs," Advances in Earth Science, vol. 29, pp. 624-631, 2014.

[66] A. C. Bumb and C. R. McKee, "Gas-well testing in the presence of desorption for coalbed methane and Devonian shale," SPE Formation Evaluation, vol. 3, no. 1, pp. 179-185, 2013.

[67] H. S. Lane, A. T. Watson, and D. E. Lancaster, "Identifying and estimating desorption from Devonian shale gas production data," in Proceedings of the SPE Annual Technical Conference and Exhibition, San Antonio, Texas, October, 1989.

[68] J. P. Spivey and M. E. Semmelbeck, "Forecasting long-term gas production of dewatered coal seams and fractured gas shales," in Proceedings of the Low Permeability Reservoirs Symposium, Denver, Colorado, March, 1995.

[69] R. M. Bustin, C. R. Clarkson, and J. P. Seidle, "Production-data analysis of single-phase (gas) coalbed-methane wells," SPE Reservoir Evaluation \& Engineering, vol. 10, no. 3, pp. 312-331, 2007.

[70] V.Shabro, C. Torres-Verdin, and K. Sepehrnoori, "Forecasting gas production in organic shale with the combined numerical simulation of gas diffusion in kerogen, Langmuir desorption from surfaces, and advection in nanopores," in Proceedings of the SPE Annual Technical Conference and Exhibition, San Antonio, Texas, USA, October, 2012.

[71] V. Swami, A. T. Settari, and F. Javadpour, "A numerical model for multi-mechanism flow in shale gas reservoirs with application to laboratory scale testing," in Proceedings of the EAGE Annual Conference \& Exhibition incorporating SPE Europec, London, UK, June 2013.

[72] S. Harpreet, F. Javadpour, A. Ettehadtavakkol, and H. Darabi, "Nonempirical apparent permeability of shale," SPE Reservoir Evaluation \& Engineering, vol. 17, no. 3, pp. 414-424, 2014.

[73] F. Civan, "Effective correlation of apparent gas permeability in tight porous media," Transport in Porous Media, vol. 82, no. 2, pp. 375-384, 2009.

[74] D. Ding, C. Wang, D. Didier, and Y. Wu, "Characterizing hydraulic fractures in shale gas reservoirs using transient pressure tests," in Proceedings of the SPE Hydraulic Fracturing Technology Conference, The Woodlands, Texas, USA, February, 2013. 
[75] B. Song, Pressure transient analysis and production analysis for New Albany shale gas wells, Diss. Texas A\&M University, 2010.

[76] Z. Yu-long, Z. Lie-Hui, F. Guo-Qing, Z. Bo-Ning, and K. Bo, "Performance analysis of fractured wells with stimulated reservoir volume in coal seam reservoirs," Oil \& Gas Science and Technology, vol. 71, no. 1, pp. 8-8, 2016.

[77] L. Zhang, Z. Kou, H. Wang et al., "Performance analysis for a model of a multi-wing hydraulically fractured vertical well in a coalbed methane gas reservoir," Journal of Petroleum Science \& Engineering, vol. 166, pp. 104-120, 2018.

[78] G. J. I. Igwe, "Gas transport mechanism and slippage phenomenon in porous media," in Proceedings of the SPE Conference, Richardson, Texas, USA, 1985.

[79] R. Zhang, L. Zhang, R. Wang, Y. Zhao, and D. Zhang, "Research on transient flow theory of a multiple fractured horizontal well in a composite shale gas reservoir based on the finite-element method," Journal of Natural Gas Science and Engineering, vol. 33, pp. 587-598, 2016.

[80] Y. Li, Y. Wang, J. Wang, and Z. Pan, "Variation in permeability during CO2-CH4 displacement in coal seams: part 1 - experimental insights," Fuel, vol. 263, p. 116666, 2020.

[81] Y. Li, D. Tang, H. Xu, Y. Meng, and J. Li, "Experimental research on coal permeability: the roles of effective stress and gas slippage," Journal of Natural Gas Science and Engineering, vol. 21, pp. 481-488, 2014.

[82] Y. Zhao, L. Liu, L. Zhang, X. Zhang, and B. Li, "Simulation of a multistage fractured horizontal well in a tight oil reservoir using an embedded discrete fracture model," Energy Science \& Engineering, vol. 7, no. 5, pp. 1485-1503, 2019.

[83] S. Zhou, Y. Ning, H. Wang, H. Liu, and H. Xue, "Investigation of methane adsorption mechanism on Longmaxi shale by combining the micropore filling and monolayer coverage theories," Advances in Geo-Energy Research, vol. 2, no. 3, pp. 269281, 2018.

[84] H. Singh and J. Cai, "A mechanistic model for multi-scale sorption dynamics in shale," Fuel, vol. 234, pp. 996-1014, 2018.

[85] H. Wang, "Performance of multiple fractured horizontal wells in shale gas reservoirs with consideration of multiple mechanisms," Journal of Hydrology, vol. 510, pp. 299-312, 2014. 